\title{
Treatment Optimization in MS: Canadian MS Working Group Updated Recommendations
}

\author{
Mark S. Freedman, Daniel Selchen, Douglas L. Arnold, Alexandre Prat, \\ Brenda Banwell, Michael Yeung, David Morgenthau, Yves Lapierre, on behalf \\ of the Canadian Multiple Sclerosis Working Group*
}

\begin{abstract}
The Canadian Multiple Sclerosis Working Group (CMSWG) developed practical recommendations in 2004 to assist clinicians in optimizing the use of disease-modifying therapies (DMT) in patients with relapsing multiple sclerosis. The CMSWG convened to review how disease activity is assessed, propose a more current approach for assessing suboptimal response, and to suggest a scheme for switching or escalating treatment. Practical criteria for relapses, Expanded Disability Status Scale (EDSS) progression and MRI were developed to classify the clinical level of concern as Low, Medium and High. The group concluded that a change in treatment may be considered in any RRMS patient if there is a high level of concern in any one domain (relapses, progression or MRI), a medium level of concern in any two domains, or a low level of concern in all three domains. These recommendations for assessing treatment response should assist clinicians in making more rational choices in their management of relapsing MS patients.
\end{abstract}

RÉSUMÉ: Optimisation du traitement dans la sclérose en plaques : mise à jour des recommandations du Canadian MS Working Group. Le Canadian Multiple Sclerosis Working Group (CMSWG) a élaboré des recommandations pratiques en 2004 pour aider les cliniciens à optimiser l'utilisation des traitements modificateurs de la maladie chez les patients atteints de sclérose en plaques récurrente-rémittente (SPRR). Le CMSWG s'est réuni pour réviser comment est évaluée l'activité de la maladie, pour actualiser l'évaluation d'une réponse sous-optimale et pour suggérer un plan de changement ou d'intensification du traitement. Des critères pratiques pour évaluer les épisodes de récurrence ainsi que la progression telle qu'évaluée par l'Expanded Disability Status Scale (EDSS) et l'IRM ont été développés pour classifier le niveau de préoccupation clinique comme étant faible, moyen ou élevé. Le groupe a conclu qu'un changement de traitement peut être envisagé chez tout patient atteint de SPRR s'il existe de vives préoccupations dans l'un ou l'autre domaine, soit les épisodes de récurrence, la progression ou l'IRM, un niveau de préoccupation modéré dans deux domaines, ou un faible niveau de préoccupation dans les trois domaines. Ces recommandations pour l'évaluation de la réponse au traitement devraient aider les cliniciens à faire des choix plus rationnels dans la gestion des patients atteints de SPRR.

Can J Neurol Sci. 2013; 40: 307-323

It has been almost two decades since the publication of the pivotal trial results for the first of the disease-modifying therapies (DMT) for relapsing-remitting multiple sclerosis (RRMS). In the intervening years, DMTs - interferon (IFN) $\beta-1 b$, IFN $\beta$-1a, glatiramer acetate - have become the standard of care for patients with RRMS.

To assist clinicians in their assessment of patient response to DMTs and to improve clinical outcomes, in 2004 the Canadian Multiple Sclerosis Working Group (CMSWG) developed practical recommendations on treatment optimization using the best available evidence at that time. ${ }^{1}$ Since the publication of that document, considerable advances have been made in our understanding of the natural history of multiple sclerosis (MS) and the immunopathological changes that occur. There is now a greater awareness that MS is not an uncommon finding in children and adolescents and research in this area may shed new light on the relative contributions of genetic and environmental factors to the etiology of MS.

The prospect that treatment may modify the disease course has enabled clinicians to intervene promptly after a first clinical attack in patients with magnetic resonance imaging (MRI) features strongly supportive of MS as soon as MS-like central nervous system (CNS) demyelination is detected. With clinically isolated syndrome (CIS) consistent with a first attack of MS, large, randomized controlled studies - CHAMPS, ETOMS, BENEFIT, PRECISE, REFLEX - have now demonstrated that DMTs can prolong the time to confirmed "clinically-definite" MS, ${ }^{2-6}$ ("clinically definite MS" [CDMS]) is an outdated definition based on having additional relapses that pre-dated the use of MRI). However, it remains to be determined if earlier treatment will improve longer term disability outcomes in patients treated from the first MS attack. ${ }^{7,8}$ Several iterations of

From the Ottawa Hospital Research Institute (MSF), University of Ottawa, Ottawa; St Michael's Hospital (DS, DM), Toronto; The Hospital for Sick Children (BB), Toronto, Ontario; Montreal Neurological Institute and Hospital (DLA, YL); Centre hospitalier de l'Université de Montréal (AP), Montreal, Quebec; Foothills Medical Centre (MY), Calgary, Alberta, Canada

Received October 26, 2012. Final Revisions Submitted January 2, 2013. Correspondence to: Mark S. Freedman, University of Ottawa, Multiple Sclerosis Research Unit, The Ottawa Hospital-General Campus, 501 Smyth Road, Ottawa, Ontario, K1H 8L6, Canada. Email: mfreedman@toh.on.ca. 
the newer diagnostic criteria have made all of the CIS trials somewhat obsolete, as up to one-half of the patients in these trials would today probably fulfill criteria to be called "MS".9,10

The previous CMSWG recommendations did not consider cognitive change except as a factor influencing measures of progression. It is now well established that cognitive impairment may be detected in $20-30 \%$ of patients at the time of a first MS attack. ${ }^{11-14}$ An estimated $40-65 \%$ of MS patients will demonstrate cognitive dysfunction at some point in their illness, ${ }^{15}$ with prevalence increasing with age and duration of MS. ${ }^{16}$ The importance of cognitive change to patients' employment, daily functioning and quality of life, methods of assessing cognitive dysfunction in practice, and the clinical usefulness of these measures in the overall evaluation of treatment response were the subjects of much discussion in our drafting of the current recommendations.

The rapid pace of MS research over the past decade had led to two new DMTs since our initial recommendations. The monoclonal antibody natalizumab has been shown to be effective, ${ }^{17,18}$ but long-term use has been limited by the risk of progressive multifocal leukoencephalopathy (PML) arising from John Cunningham (JC) virus reactivation. A great deal of work has been done to quantify the risk of PML during treatment with natalizumab, and the recent approval of a JC virus antibody test in Canada should assist clinicians in individualizing treatment decisions. However, proposed strategies ${ }^{19}$ for reducing the risk of developing PML await validation. Fingolimod, the first oral DMT, has also been shown to be efficacious in RRMS, ${ }^{20,21}$ but has worrisome side effects that require careful patient selection and post-treatment vigilance. These new therapies will likely be joined in Canada by numerous other treatments in development, such as teriflunomide, BG-12, laquinimod, and alemtuzumab. Our therapeutic options have broadened considerably in the past eight years and decision-making will become increasingly complex in the years ahead. These considerations prompted the CMSWG to re-examine and update its treatment optimization recommendations to assist clinicians in their management of relapsing MS patients.

The overall goals of this paper are to review how disease activity is assessed; propose a more current, rational approach for assessing suboptimal response and to suggest a scheme for switching or escalating therapy; discuss ways to evaluate cognition and how cognitive changes fit into the clinical assessment of disease activity; review how these approaches might be applied to the pediatric population; and address some of the other treatment issues, such as monitoring for drug antibody formation.

\section{MethodOLOGY}

The objectives of this consensus document were to update the CMSWG's previous recommendations on how neurologists can assess the status of patients on DMTs, and to determine at what point in a course of therapy it may be necessary to modify treatment to optimize patient outcomes. The initial model, adapted from a similar one proposed by Bashir et al, ${ }^{22}$ was based on relapses, disease progression as measured by the Expanded Disability Status Scale (EDSS) (or EDSS progression), and MRI outcomes. Criteria were developed for determining the level of concern for each of these areas to indicate to clinicians when to consider treatment modification.
To update its recommendations, the CMSWG formed eight subgroups to review the literature and develop recommendations.

The subgroups (and team leaders) were Relapses (YL), MRI (DLA), Cognition (DS), Progression (MSF), Pediatric MS (BB), Treatment-Initiation (MY), Treatment-Switching (AP), and Other Issues (DM). A Medline search using the search term 'multiple sclerosis' was performed to obtain all relevant papers for the period 2004 to 2011 . Following a review of the literature and a series of meetings of the subgroups, the CMSWG met in December 2011 to discuss its findings. Recommendations were in accordance with published evidence and, where data were lacking, on group consensus based on clinical experience.

\section{Relapses}

The revised McDonald criteria define a relapse as: “...[P]atient-reported symptoms or objectively observed signs typical of an acute inflammatory demyelinating event in the CNS [central nervous system], current or historical, with duration of at least 24 hours, in the absence of fever or infection. Although a new attack should be documented by contemporaneous neurological examination, in the appropriate context, some historical events with symptoms and evolution characteristic for $M S$, but for which no objective neurological findings are documented, can provide reasonable evidence of a prior demyelinating event." 10

McDonald et al also stated that 30 days should separate the onset of the first event from the onset of a second event. ${ }^{23}$

The CMSWG was in agreement with these revised definitions. However, it was noted that duration of 24 hours may be too brief and could allow poorly explained fluctuations or pseudorelapses to be counted as relapses; a minimal duration of 48 hours, as used in many clinical trials, may more accurately reflect true relapses (i.e. indicating CNS inflammatory activity). In addition, it was noted that the criterion of a 30-day interval separating relapses is somewhat arbitrary since the mechanisms leading to localized acute CNS inflammation and the time course for these processes are not known.

The overall goal of instituting therapy as early as possible in patients either at very high risk of developing repeated MS activity or in patients meeting diagnostic criteria for MS is to suppress early clinical and sub-clinical attacks believed to contribute eventually to long-term disability. ${ }^{24-26}$ Though the overall contribution of relapses to disability progression is debatable once actual disability is evident, ${ }^{27}$ natural history has shown that relapses in the first two years of disease impact early progression. ${ }^{28}$ This emphasizes the importance of early successful control of disease activity to prevent the accumulation of disability. A caveat is that there are no long-term studies of sufficient duration to allow us to be sure that this strategy will prevent or delay the onset of secondary-progressive disease. ${ }^{29}$

Although we have relied on clinically evident relapses as an indicator of poor treatment response in the past, the sole use of relapse rate per se may not be sufficient. Relapses are subject to recall bias by patients, and observer bias by clinicians; Thygesen found that relapse rates decline with less frequent observation (e.g. 1.2 at three weeks and 0.5 at three months) ${ }^{30}$ Interpretation of the effects of treatment on relapses is complicated by the successive decline in overall annualized relapse rates (ARR), as is evident in looking at the clinical trials over the past two 
decades. ${ }^{31}$ For example, in the pivotal trial of IFN $\beta-1 b$ in 1993 , the ARR for the placebo arm was $1.27 ;^{32} 17$ years later, the ARR for the placebo group in the pivotal trial of fingolimod was $0.40 .^{20}$ In line with this observation, a systematic review found that the placebo ARR is declining about $6 \%$ per year. ${ }^{33}$ In clinical practice, relapse rates have been reported to decrease by $17 \%$ every five years in patients not exposed to a DMT. ${ }^{34}$ This relapse decline may reflect the type of patients recruited to more contemporary trials, especially with the change in diagnostic criteria favouring earlier diagnosis and translating to including patients earlier in their disease course. It may also reflect that in more contemporary studies, patients are often asked to decline conventionally available therapies to enter a trial and referring physicians may be biasing their recruitment to patients perceived to have less of a risk of relapse, especially if the trial includes a placebo arm.

RECOMMENDATIONS FOR DETERMining THE LEVEL OF Concern with Regard to Considering Treatment MODIFICATION BASED ON RELAPSES

Despite these limitations, population-based studies have indicated that the number of relapses during the first two years of MS is predictive of long-term disability. ${ }^{28,35}$ The prognostic value beyond the first five years appears to be minimal. ${ }^{26}$ For treated cohorts, the relapse rate in the first year of treatment appears to be correlated with short-term disability; ${ }^{36}$ this correlation is more robust when relapse rate and MRI lesion activity at one year of treatment are combined. ${ }^{37}$

Given that some patients will be treated today after having only a single attack, it is difficult simply to use "relapse rate" to judge a change over time. Other aspects of the attack may be more important, such as location in the CNS, severity, and the degree of recovery. Of importance are symptoms indicating sphincteric, motor, cerebellar or brainstem involvement, which are associated with worse outcomes. ${ }^{38,39}$ Also important is the number of functional systems affected. ${ }^{38}$ Prognosis is poorer in patients with multifocal attacks, ${ }^{39,40}$ which indicate clinically manifested "dissemination in space" lesions.

As stated, relapse severity and the time to recovery also have clinical significance. Mowry et al found that patients with
CIS/MS who experience a severe attack and poor recovery are highly likely to continue on that same course. ${ }^{41} \mathrm{~A}$ pooled analysis of 27 studies found that incomplete recovery from the first attack and a short interval between the first and second attack were strongly associated with a poorer prognosis. ${ }^{42}$

Most EDSS progression in early disease is related to relapses that don't recover and leave sequelae..$^{24,25,43}$ Thus, the degree of recovery post-relapse, which may reflect the individual patient's innate repair mechanisms, needs to be considered in "weighting" the severity of each attack. ${ }^{44}$ This evaluation should be made promptly: a three-year retrospective study found that incomplete recovery at one month was highly predictive of residual disability at one-year follow-up. ${ }^{43}$

Recommendations for the clinical assessment of relapses, which comprises relapse rate, severity and recovery, are shown in Table 1. The criteria used differ from those previously proposed by the CMSWG in one important aspect. In 2004, the level of concern was determined in part by the percent reduction in relapse rate. However, since patients with CIS/early MS are often treated, baseline relapse rates can no longer be used as the comparator for treatment success or failure. Moreover, either changes in trial populations or the advent of perhaps more potent DMTs has made the endpoint of disease activity-free more attainable, as demonstrated in recent studies. ${ }^{45-48}$ Thus, the CMSWG recommends that any relapse during the early treatment stages should be a cause for concern. However, relapse frequency should be a major criterion for determining the need to optimize treatment, at least for the first five years of therapy. In addition, the use of well-designed diaries for patients to record relapse frequency, severity, symptoms and impact on activities of daily living is recommended.

\section{Progression}

Accumulated disability, or "progression", ultimately indicates a failure to fully control the advancement of disease. Progression occurring in relapsing patients or those with continued MRI activity is probably still amenable to treatment with agents directed at the early inflammatory component of the disease. Most early progression is the result of unresolved relapses, but this may well overshadow a more indolent

Table 1: Recommendations for determining the level of concern when considering treatment modification based on relapses.*

\begin{tabular}{|c|c|c|c|}
\hline \multirow[t]{2}{*}{ Criteria } & \multicolumn{3}{|c|}{ Level of concern } \\
\hline & Low & Medium & High \\
\hline Rate & 1 relapse in the second year of treatment & 1 relapse in the first year of treatment & $>1$ relapse in the first year of treatment \\
\hline Severity & $\begin{array}{l}\text { Mild } \\
\text { - } \quad \text { Steroids not required } \\
\text { - } \quad \text { Minimal effect on ADL } \\
\text { - } \quad \begin{array}{l}\text { No or mild motor/ cerebellar } \\
\text { involvement }\end{array}\end{array}$ & $\begin{array}{ll}\text { Moderate } \\
\text { - } & \text { Steroids required } \\
\text { - } & \text { Moderate effect on ADL } \\
\text { - } & >1 \text { functional domain affected } \\
\text { - } & \text { Moderate motor/ cerebellar } \\
& \text { involvement }\end{array}$ & \begin{tabular}{ll}
\multicolumn{2}{l}{ Severe } \\
- & Steroids/ hospitalization required \\
- & Severe effect on ADL \\
- & $\quad$ Severe motor/ cerebellar \\
& involvement
\end{tabular} \\
\hline $\begin{array}{l}\text { Recovery } \\
\text { (duration) }\end{array}$ & $\begin{array}{ll}\text { - } & \text { Prompt recovery } \\
\text { - } & \text { No functional deficit }\end{array}$ & $\begin{array}{l}\text { - } \quad \text { Incomplete recovery at } 3 \text { months } \\
\text { - } \quad \text { Some functional impairment }\end{array}$ & $\begin{array}{ll}\text { - } & \text { Incomplete recovery at } 6 \text { months } \\
\text { - } & \text { Functional impairment }\end{array}$ \\
\hline
\end{tabular}

* The level of concern determined by meeting at least one criterion. ADL=activities of daily living 
progressive process that only manifests once relapses cease and there is perception of disease worsening. The Kurtzke EDSS ${ }^{49}$ is the most commonly used standardized and validated measure of disease progression. To calculate the EDSS (or Neuro Status variation), an objective measurement of ambulation is required that will indicate whether a patient can walk without rest or aid for 100-500 meters (20-100 m if a walking aid is required). An observed walk of up to $500 \mathrm{~m}$ is generally impractical because of the time involved and physical restraints of the clinic space. This is not an issue for EDSS scores <4.0, but is key for higher EDSS values, particularly 4.0-7.0.

If observation is not feasible, the clinician must estimate the distance a patient is able to walk. One solution to improve accuracy might be a validated tool that allowed patients to report the distance they are able to walk; this tool could include reference distances, e.g. $100 \mathrm{~m}$ (110 yards $)=$ one North American city block or the length of a Canadian football field. The length of hallways the patient must use to get from the elevator to the office, or the distance from the parking lot to the clinic, can be calculated and may aid in estimations of ambulation. The use of GPS-enabled devices such as smart phones or pedometers may be of use in the future for determining distances walked.

Patients should be encouraged to consider best unaided walking distance. For example, patients may use a cane for security or comfort but do not actually require it. An inability to walk without a cane requires a minimum EDSS score of 6.0; however, if a cane is not actually required to walk distances of 100 or $200 \mathrm{~m}$, the EDSS would drop to 5.5 or 5.0, respectively. It is important to assess changes accurately in this EDSS range since even half-point increases can be interpreted as significant progression. In addition, if the EDSS is overestimated (e.g. a score of 6.0 because the patient prefers to use a cane), the measure will become insensitive to change over the ensuing years.

An alternative to the EDSS is the Multiple Sclerosis Functional Composite (MSFC), ${ }^{50}$ which comprises quantitative functional measures of ambulation, arm and hand function, and cognition. However, the MSFC takes time to administer, requires a separate examiner, can result in some patient discomfort (related to the anxiety often associated with the cognitive test called the Paced Auditory Serial Addition Test [PASAT]), and the overall score does not allow for ready interpretation in the absence of a standardized reference population.

One component, the Timed 25-foot walk (T25FW), is relatively easy to administer and has shown consistency and validity. ${ }^{51-53} \mathrm{~A}>20 \%$ change in T25FW correlates with EDSS changes and provides independent information. The CMSWG believes that the $\mathrm{T} 25 \mathrm{FW}$ as part of the routine assessment would have practical benefits and may be a more sensitive measure of progression in some patients, at least in patients with EDSS scores $>4.0 .^{54}$ Given that this is the same population in which objective assessment of a 500-metre walk is not practical, the short time it takes to perform the T25FW makes it a complementary assessment to the EDSS. It has also become the most important test for assessing the response to fampridine, ${ }^{55}$ and hence could become routinely used in MS clinics. Studies have shown variability in the $\mathrm{T} 25 \mathrm{~W}$ times of up to $20 \%$, so changes $>20 \%$ of baseline are considered meaningful. However, assessments must consider factors that may influence ambulatory ability, such as activity prior to the assessment, distance walked to the clinic, ambient temperature, fatigue, depression, cognitive function, coexisting medical conditions and simply whether or not it was a "good day." Ideally, serial walking tests would be performed at the same time (e.g. in the morning) and in the same setting, although this can be difficult in practice.

Assessments performed annually would be reasonable for stable patients. More frequent assessments (minimum every three to six months) are advised for patients with more active disease. Any changes should be confirmed with a follow-up assessment to exclude periodic fluctuations. In the clinical trial setting, disease progression is often confirmed at three or six months, although some have suggested confirmation at one to two years to exclude short-term fluctuations. However, in clinical practice this would seem to be an unreasonable delay for a change in treatment if a patient is demonstrating progression.

Other patient-based assessment scales may also be considered. For example, Hobart et al have developed the 12item MS Walking Scale, a patient self-reported measure of walking ability. ${ }^{56}$ This scale has been shown to be a reliable, valid and responsive measure of walking ability in MS, and may offer a more simple and flexible measurement of walking distance in clinical practice. Other self-report questionnaires of disability and impairment (e.g. Minimal Record of Disability, ${ }^{57}$ The Symptom Inventory and The Performance Scales ${ }^{58}$ ) have been shown to have overall moderate correlations with physician ratings of disability and may be considered when assessing disease progression.

The increased availability of MRI has largely eclipsed other paraclinical surrogates of disease progression. Invernizzi et al have reported that evoked potentials (EP) have some prognostic value ${ }^{59}$ but this requires further study. There are no data from immunological or pathological studies to indicate when a change in therapy should be made. Neurofilament proteins in cerebrospinal fluid (CSF) have been proposed as a marker of axonal damage and may have prognostic value for conversion of CIS to MS and for disease progression in MS; ${ }^{60}$ while this is promising, more research is required.

\section{RECOMMENDATIONS FOR DETERMining THE LEVEL OF Concern with Regard to Considering Treatment Modification Based on Disease Progression}

The CMSWG recognizes that the treatments available to date have not conclusively shown a beneficial long-term effect on disease progression in MS or CIS..$^{7,8,61-64}$ While a certain proportion of patients who appear to fail treatment may show some response with longer follow-up, ${ }^{65}$ sustained progression mandates consideration of a treatment change. Rio et al reassessed the clinical usefulness of different treatment failure criteria and found that a combination of either relapse or EDSS progression criteria together with MRI changes were sensitive at one year to predict continued activity should a patient remain on the same therapy. ${ }^{66}$ These findings led to the current recommendation that treatment modification based on disability progression alone requires some confirmation at three to six months from the time it is first suspected. However, unconfirmed disability progression in conjunction with a substantial MRI change could also prompt a change in treatment. Expanded 
Table 2: Recommendations for determining the level of concern when considering treatment modification based on disability progression

\begin{tabular}{|c|c|c|c|}
\hline Criteria & \multicolumn{3}{|c|}{ Level of concern } \\
\hline EDSS score & Low & Medium & High \\
\hline$\leq 3.5$ & $\leq 1$ points & 2 points at 6 months $*$ & $\begin{array}{l}>2 \text { points at } 6 \text { months* } \\
2 \text { points at } 12 \text { months* }\end{array}$ \\
\hline 4.0 to 5.0 & $<1$ point & 1 point at 6 months* & $\begin{array}{l}>1 \text { point at } 6 \text { months* } \\
1 \text { point at } 12 \text { months* }\end{array}$ \\
\hline$\geq 5.5$ & & 0.5 points at 6 months $*$ & $>0.5$ points at 6 months \\
\hline $\begin{array}{l}\text { Clinically documented } \\
\text { progression }\end{array}$ & $\begin{array}{l}\text { No motor } \\
\text { Minor sensory }\end{array}$ & $\begin{array}{l}\text { Some motor, cerebellar or cognitive } \\
\text { Multiple EDSS domains affected }\end{array}$ & $\begin{array}{l}\text { Pronounced motor, cerebellar or cognitive } \\
\text { Multiple EDSS domains affected }\end{array}$ \\
\hline $\mathrm{T} 25 \mathrm{FW} * *$ & $\leq 20 \%$ confirmed at 6 months & $\begin{array}{l}>20 \% \text { and }<100 \% \text { increase } \\
\text { confirmed at } 6 \text { months }\end{array}$ & $\begin{array}{l}\geq 100 \% \text { increase } \\
\text { confirmed at } 6 \text { months }\end{array}$ \\
\hline
\end{tabular}

*If EDSS progression alone is used to assess response to treatment, any change requires subsequent confirmation at 3-6 months.

**Timed 25-foot Walk tested at baseline with aid, if required

Disability Status Scale changes due to changes in multiple domains of the EDSS (the Kurtzke functional subscores such as motor and cerebellar) are clinically worrisome, and although evidence is lacking for any strong association with sustained disability progression, the CMSWG recommends that this be viewed with a high level of concern.

Table 2 summarizes the recommendations for determining the level of concern with regard to considering treatment modification based on disability progression. These recommendations assume an observation period of at least one year. The time of treatment initiation is important in judging what change might be due to natural history rather than an inadequate treatment effect.

From the pivotal clinical trials, a beneficial effect on either relapses or MRI can generally be observed within about three to six months of initiating a DMT. ${ }^{67}$ In the first year of therapy, signs of progression may reflect disease activity that occurred prior to starting treatment rather than a failure of the treatment to affect progression. Since a three-month confirmation could still be detecting resolving effects of relapse, the CMSWG recommends that progression of disability be confirmed at six months; confirmation at 12 months may be advised in clinical trials but is too stringent for clinical practice. A six-month sustained change in EDSS score $\geq 2$ is a concern in patients with EDSS $\leq 3.5$; smaller EDSS changes are a concern in patients with greater disability (Table 2) ${ }^{68,69}$ Changes on the T25FW and clinically documented progression will further inform the clinician's level of concern for an individual patient.

The EDSS change, in conjunction with active MRI changes or ongoing relapses, represents an inadequate treatment response. In the second and subsequent years of treatment, progression alone probably becomes a better indicator of a suboptimal treatment response.

When assessing progression, it is important to document the functional subscales that are having the most impact on the EDSS score. Determining true progression requires that changes seen in one or more functional systems are maintained over time. The Neuro Status is an interpretive EDSS that downgrades changes in ocular or bladder domains of the EDSS so that subjective changes alone in these domains will not greatly affect EDSS. Otherwise, blindness in one eye with a Visual Functional
System score of 5.0 could make the overall EDSS 5.0 (where patients are limited to walking no more than $200 \mathrm{~m}$ ), even though the patient's walking ability may be unimpaired.

\section{Magnetic Resonance Imaging}

Although the diagnostic value of MRI in MS is well established, the clinical usefulness of routine MRI for monitoring the evolution of patients with MS is less widely accepted. It is clear that MRI (especially only of the brain) is not always well correlated clinically with either relapses or progression. Thus, lack of inflammatory changes on the MRI should not be necessarily construed as a sign of disease control. Alternatively, when the MRI is active, it can reveal important information about disease control. The following summarizes some of the evidence that follow-up MRI of MS patients starting on a DMT provides important information about disease activity that is predictive of relapse and progression. Since clinical practice does not include quantitative assessment of lesion volume or non-lesional pathology, such as atrophy, the discussion below is limited to the visual assessment of new T2weighted lesions and contrast-enhancing (Gd-enhancing) T1weighted lesions.

The significance of MRI lesions in comparison to relapses is often questioned. In a randomized, placebo-controlled clinical trial of IFN $\beta$-1a therapy for RRMS, Rudick et al. found that $\geq 2$ Gd-enhancing lesions on MRI over two years were two-fold more predictive of EDSS progression than relapses; $\geq 3$ or more new T2 lesions were 3.4 times more predictive than relapses. ${ }^{70}$ Thus, the evidence does not support the presumption that relapses are more important than MRI lesions as predictors of suboptimal response to therapy.

A number of studies have attempted to define poor responders to therapy and to identify standard MRI features that are predictive of poor response. In patients with RRMS, $\geq 1$ new gadolinium-enhancing lesions or new T2 lesions after one year on therapy with IFN $\beta$ is associated with an approximate three to eight times higher risk of having $\geq 2$ or more relapses (suboptimal treatment response) over the next four to five years. ${ }^{71,72}$ In the study by Tomassini et al, the presence of Gdenhancement or black holes at baseline was also associated with 
higher relapse rate (Gd-enhancement) and disability progression (black holes) on treatment over the next five years. ${ }^{72}$

In a follow-up of two to three years, Prosperini and colleagues assessed the risk of EDSS progression associated with the presence of new T2 lesions on a scan one year after initiating therapy. ${ }^{73}$ They found that the risk of EDSS progression was increased about 10 -fold for a single new T2 lesion, about 20 -fold for two new T2 lesions, and about 30 -fold for $\geq 3$ new T2 lesions. Similarly, Rio and colleagues reported an approximate 10-fold increase in the risk of progression over two years for patients with active lesions on MRI obtained one year after initiating therapy. ${ }^{74} \mathrm{An}$ increase of $\geq 5 \mathrm{Gd}$-enhancing lesions in serial scans of a patient is associated with a significantly increased risk of a relapse within the next month. ${ }^{75}$

Recently, Sormani et al have analysed the Prevention of Relapses and disability by Interferon beta-1a Subcutaneously in Multiple Sclerosis (PRISMS ${ }^{76}$ ) dataset to determine the predictive value of a combined metric of new T2 lesions and relapses at one year after treatment initiation as a surrogate for disability progression. ${ }^{37}$ Patients were assigned a modified Rio score based on new T2 lesions $(>5=1$ point) and relapses ( 1 relapse $=1$ point; $>2$ relapses $=2$ points). Scores ranged from 0 (new T2 lesions $<5$, no relapses) to 3 (new T2 $>5,>2$ relapses). The risk of disease progression at three years (four years after starting treatment) for patients considered to be treatment responders (score 0 or 1 ) was $32-42 \%$, and for treatment nonresponders (score 2 or 3 ) was $50 \%$. Thus, the combination of MRI lesions and relapses after treatment initiation appears to be a reasonable surrogate of disease progression.

\section{RECOMMENDATIONS FOR DETERMining THE LEVEL OF CONCERN BASED ON MRI}

Recommendations for levels of concern based on MRI are shown in Table 3. In keeping with the trend in recent guidelines,${ }^{10}$ these recommendations expand the role of MRI in determining the level of concern regarding a suboptimal response to therapy compared to the previous CMSWG recommendations.

The basic concept underlying these recommendations is that ongoing focal white-matter inflammation in the setting of a therapy that is supposed to modulate this inflammation (particularly IFN $\beta$ ) is an indicator of suboptimal treatment response. ${ }^{77}$ In keeping with this, we have combined new Gd- enhancing lesions and new T2 lesions as markers of focal whitematter inflammation.

However, there are subtle differences in the significance of new Gd-enhancing lesions and new T2 lesions. Gd-enhancement has the advantage in that it clearly indicates active inflammation at the time of the scan; new T2 lesions integrate activity that has occurred in the interval between the scans being compared. Thus, new $\mathrm{T} 2$ lesions have to be interpreted in terms of the timing of the reference scan and the pharmacodynamics of the therapy. As some drugs may take up to six months to become effective, it is recommended that an MRI that will be used as a reference to assess new $\mathrm{T} 2$ lesion formation be obtained at least six months after initiating therapy, so that new T2 lesions on subsequent follow-up scans can be interpreted without the uncertainty of whether they developed before the drug became effective. In some cases it may not be possible to get MRI scans at the most opportune times and a reference scan obtained around the time of starting a new therapy may have to be used. In such cases, new T2 lesions on a follow-up scan would need to be interpreted in the context of the level of disease activity at the time treatment was initiated, and the time required for the new therapy to become effective.

Another benefit of using Gd enhancement rather than T2 lesions is that it is less subject to the technique used to obtain the MRI and there are fewer uncertainties in the comparison of paired scans. If MRI lesions are to be used to modify therapy, rigorous review by an individual experienced in the assessment of MS and related disorders who has access to comparison with relevant previous scans is essential to verify the presence of new $\mathrm{T} 2$ or Gd-enhancing lesions. In the case of new T2 lesions, it may be very difficult to be sure about the formation of new lesions, especially if they are small and comparison is made in poorer quality "non-study grade" scans, possibly from different scanners.

There are a number of issues that are not addressed by the above recommendations. The long-term use of MRI beyond two years after treatment initiation has not been discussed due to a lack of published evidence. The use of spinal imaging has also not been discussed, in part for the same reason and in part because it will have a small yield due to technical challenges in acquiring and interpreting these images. Moreover, most patients with spinal lesions will also have lesions in the brain, which represents a much larger proportion of the CNS.

Table 3: Recommendations for determining the level of concern when considering treatment modification based on annual MRI findings

\begin{tabular}{l|c|c|c}
\hline & \multicolumn{3}{|c}{ Level of concern } \\
\hline Activity on MRI* & Low & Medium & High \\
\hline $\begin{array}{l}\text { New Gd-enhancing lesions OR } \\
\text { Accumulation of new T2 lesions per year }\end{array}$ & 1 lesion & 2 lesions & \\
\hline
\end{tabular}

Note: Routine follow-up MRI with gadolinium $(G d)$ is recommended 6-12 months after initiating therapy for RRMS (or in CIS if therapy is not initiated). Note: New T2 lesions that are also enhancing on the same scan are only counted once as unique active lesions. *The presence of Gd-enhancing lesions is more reliable than new T2 lesion counts. New T2 lesion counts require highquality comparable MRI scans and interpretation by highly qualified individuals ${ }^{77}$. 
The use of atrophy as a marker of suboptimal treatment response has not been addressed, although there is evidence that some drugs slow atrophy more than others,,$^{20,78}$ and that atrophy is a predictor of clinical disease progression. ${ }^{79,80}$ However, there is still insufficient evidence to support the assertion that atrophy alone signals a suboptimal response to treatment that warrants a change in therapy. It is important to understand the time course of brain volume loss, as the biological processes that underlie brain volume loss may be operative several years before brain volume reduction is appreciated. As such, intervention with a therapeutic agent after the degenerative process has commenced may help to reduce future atrophy, but may be ineffective in limiting the tissue loss ascribed to pre-existing damage. Quantitation of brain volume requires rigorous computer analyses, which are not readily available in clinical practice.

\section{Cognition}

The previous CMSWG recommendations did not consider cognitive change except as a factor influencing measures of progression. Routine cognitive assessment was not recommended due to the absence of easy-to-use standardized scales and a paucity of evidence that treatment modification affects cognitive function.

It is well established that cognitive impairment is present early in a significant proportion of patients with CIS and MS. ${ }^{11-13}$ Cognitive dysfunction may be detected in $20-30 \%$ of patients with CIS, with significant impairment a further risk factor for progression to MS. ${ }^{14}$ An estimated 40-65\% of MS patients will demonstrate cognitive dysfunction, ${ }^{15}$ with prevalence increasing with age and duration of MS. ${ }^{16}$ Affected neurocognitive domains are processing speed, sustained attention/vigilance and episodic memory, with verbal fluency and executive function less frequently involved; 81,82 intelligence/ IQ is not affected. Cognitive impairments have a significant impact on activities of daily living, social functioning, employment and quality of life in MS. ${ }^{83-85}$

Accordingly, the CMSWG recommends that all MS patients be screened for cognitive impairment at diagnosis to establish a baseline level of functioning. Follow-up testing is recommended every two to three years post-diagnosis. More comprehensive testing, including full neuropsychological assessment, is advised if available. More frequent testing is recommended if cognitive worsening is suspected by the clinician, patient or family member.

The recommended test to evaluate cognitive function (notably processing speed and working memory) is the Symbol Digit Modalities Test (SDMT), ${ }^{86}$ which requires subjects to match symbols and numbers in 90 seconds. The test can be administered and scored in less than five minutes, and maintains its validity with repeated testing. ${ }^{87,88}$ Worsening on the SDMT over time has been shown to predict changes in employment status over time. ${ }^{89}$

The clinical assessment of cognitive impairment may be confounded by coexisting fatigue and depression. ${ }^{90}$ In addition, patient self-reports of cognitive symptoms may not be accurate and are often influenced by mood and personality factors. ${ }^{91,92}$ Some symptoms (e.g. cognitive slowing) may indicate cognitive impairment or depression; and depression may result in a poorer performance on neuropsychological testing of attention and memory. ${ }^{93}$ Accordingly, the CMSWG recommends the assessment of depression and fatigue as part of the routine management of all MS patients throughout the clinical course. Depression may be evaluated with the Beck Depression Inventory-Fast Screen (BDI-FS), a seven-item questionnaire that assesses mood, self-evaluation, anhedonia, and suicidal ideation. This tool has been validated in MS and is recommended. ${ }^{94}$ Also recommended is the 21-item Modified Fatigue Impact Scale (MFIS), which evaluates the impact of fatigue on physical, cognitive and psychosocial functioning. ${ }^{95}$ These assessments (SDMT, BDI-FS, MFIS) can be completed by clinicians in approximately 15 minutes. If clinical depression is diagnosed, the CMSWG recommends treatment with an antidepressant either alone or in combination with cognitive-behavioural therapy (CBT). ${ }^{96-101}$

There are some data indicating that MS therapies may stabilize or improve cognitive impairment, ${ }^{102-106}$ but the evidence is limited. There is insufficient evidence to indicate the superiority of one DMT over another as a guide to treatment selection. There is no convincing evidence that other agents (e.g. cholinesterase inhibitors, ginkgo biloba) improve cognitive function in MS. ${ }^{107}$

The development of new or worsening cognitive impairment is a worrisome sign during treatment with a DMT. Apart from their significant impact on physical and social functioning, cognitive changes may be associated with relapses, ${ }^{108}$ thus detection of cognitive worsening may be an indication of MS disease activity. However, it is unclear if cognitive changes indicate disease progression in the absence of other clinical or radiological evidence of progression. There are insufficient data to identify a clinically significant change on SDMT or other measures, and so clinicians cannot assign a level of concern when deterioration in one or more domains of cognitive functioning is identified. Additional research is urgently needed to determine clinically relevant changes.

No DMT has demonstrated superiority with respect to cognitive outcomes, so it has not been established that switching therapies will improve or stabilize cognitive deterioration. Accordingly, there was a general consensus that cognitive change should not be an independent factor when assessing whether treatment should be further optimized. This recommendation will be revisited when additional data are available on the effects of DMTs on cognitive outcomes.

The use of disease activity-free (combining relapses, MRI and EDSS progression) as a trial endpoint is becoming more widespread, and it would be useful to incorporate cognitive assessment as a component of a more global metric. Data related to cognition may prove useful for future recommendations on cognitive functioning as it pertains to treatment optimization.

The onset or worsening of MS fatigue and/or clinical depression are also worrisome, but these changes do not necessarily indicate DMT failure. Thus, while fatigue and depression may require specific interventions, their presence should not influence the clinician's decisions regarding treatment optimization. 


\section{Other Possible Factors Related to Treatment Response}

\section{Neutralizing antibodies}

The CMSWG reviewed other possible factors that may contribute to a suboptimal response to DMT and which may indicate a need to change therapies. Of particular importance is the development of neutralizing antibodies (NAbs) to IFN $\beta$ or natalizumab.

The most recent estimate of the prevalence of NAbs to IFN $\beta$ is $19 \%,{ }^{109}$ with the frequency differing according to the IFN $\beta$ used. NAbs generally develop after 6-12 months of treatment; the effects are often transient, with median antibody titres typically declining with follow-up testing. ${ }^{110}$ Persistently high $\mathrm{NAb}$ titres appear to reduce the effectiveness of IFN $\beta,{ }^{111}$ and may suggest the need to switch therapies. However, the longterm clinical significance of NAbs has not been fully determined. In the BENEFIT extension study, NAb positivity was associated with increased MRI activity but there were no effects on relapse rates or progression at five years. ${ }^{112}$ The use of a biomarker, myxovirus A protein (MxA), may be more accurate in assessing the clinical impact of NAbs but is not routinely available in clinical practice. ${ }^{113}$

There was no consensus on NAb testing in clinical practice. Options include periodic NAb testing in all patients and treatment modification if persistent NAbs develop; measuring NAbs only if a change in treatment is being considered and a high titre might influence this decision; or foregoing routine $\mathrm{NAb}$ testing and basing treatment decisions on clinical outcomes.

Persistent NAbs to natalizumab have also been reported in about $6 \%$ of patients, ${ }^{114,115}$ and are associated with a reduced clinical and radiological effect as well as an increase in allergic infusion reactions. Treatment modification is advised in patients with persistent NAbs to natalizumab.

Testing for antibodies to glatiramer acetate is not required since their development does not appear to influence the drug's clinical activity. ${ }^{116}$

\section{Vitamin D}

An association between MS and sun exposure was first suggested a half-century ago, ${ }^{117}$ and epidemiological studies have shown an association between low serum 25(OH)D levels and MS risk. ${ }^{118,119}$ This has potential relevance in Canada, where low vitamin D concentrations exist in over $80 \%$ of the healthy population during the winter months. Vitamin D has been shown to have effects on immune function. ${ }^{120-122}$ Several studies have shown that low sun exposure and/or low serum $25(\mathrm{OH}) \mathrm{D}$ levels are associated with higher rates of relapses and disability progression in people with RRMS or CIS. ${ }^{123-128}$ The EPIC study reported a $15 \%$ lower risk of a new T2 lesion, a $32 \%$ lower risk of a Gd-enhancing lesion, and lower disability with each $10 \mathrm{ng} / \mathrm{mL}$ increase in serum $25(\mathrm{OH}) \mathrm{D} .{ }^{129}$ A one-year trial of vitamin $\mathrm{D}$ as an add-on to IFN $\beta$ showed improvements in MRI burden of disease, but no significant difference in ARR or accumulation of disability. ${ }^{130}$ Two other prospective trials of vitamin $\mathrm{D}_{2}{ }^{131}$ and intramuscular $\mathrm{D}_{3}{ }^{132}$ found no clinical benefit with supplementation. It has been suggested that UV exposure has beneficial immunomodulatory effects that act independently of vitamin $\mathrm{D}_{3}$ production, ${ }^{133,134}$ but this requires further study. Two phase II trials (SOLAR, EVIDIMS) will evaluate vitamin $\mathrm{D}_{3}$ as add-on therapy to IFN $\beta .^{135,136}$

As there appears to be a low risk of adverse effects with vitamin D supplementation, ${ }^{137}$ routine vitamin D supplementation in MS patients appears warranted to maintain serum $25(\mathrm{OH}) \mathrm{D}$ levels $>75 \mathrm{nmol} / \mathrm{L}{ }^{138}$ Daily doses of $2000-4000 \mathrm{IU}$ (50-100 $\mu \mathrm{g})$ are expected to be necessary to achieve this goal in Canada.

\section{Treatment INITIATION}

For the purposes of this review, MS medications have been categorized as first-, second- and third-line drugs (Table 4). It should be noted that during a course of treatment, more than one "first-line" agent may be employed. Second- and third-line agents are generally associated with higher risks of deleterious side effects or lack of proven efficacy in large phase III trials.

\section{Clinically isolated syndrome suggestive of MS}

The principal goal of treatment in patients with clinically isolated syndrome (CIS) is to delay the onset of new signs/symptoms meeting diagnostic criteria for MS. Prospective trials of IFN $\beta-1 \mathrm{a}$, IFN $\beta-1 \mathrm{~b}$ and glatiramer acetate reported that treatment reduces the risk of evolution to MS by about $45 \%$ at two to three years. ${ }^{2,4,5}$ Less benefit was seen with low-dose (22 $\mu \mathrm{g}$ once weekly) IFN $\beta-1 \mathrm{a} .^{3}$ The REFLEX study has recently shown that subcutaneous IFNB-1a 44 ug three times/week versus once/week are both effective at delaying the development of MS according to the old Poser criteria (i.e. CDMS), but that the more frequently dosed regimen was more effective at delaying the development of McDonald (2005 criteria $\left.^{9}\right)$ MS. $^{6}$

Table 4: Categories of therapies for treatment optimization in RRMS

\begin{tabular}{l|l}
\hline First line & IFN $\beta-1 \mathrm{a}$, IFN $\beta-1 \mathrm{~b}$, glatiramer acetate \\
\hline Second line & Fingolimod, natalizumab \\
\hline Third line & Mitoxantrone, alemtuzumab, cladribine (IV), cyclophosphamide \\
\hline Experimental/unproven therapies & Rituximab, daclizumab, ocrelizumab, ofatumumab, bone marrow transplant \\
\hline
\end{tabular}


While therapy may be considered for any CIS patient and generally recommended for CIS patients with a moderate to high burden of disease, the long-term benefits are uncertain. Early versus delayed treatment has been shown to reduce the rate of conversion to MS and to lower the annualized relapse rate, however, long-term disability outcomes were unaffected in the five-year follow-up of BENEFIT and in the ten-year follow-up of CHAMPS..$^{7,8}$ The decision to treat should be made on an individualized basis in consultation with the patient. If treatment is considered, then the CMSWG recommends first-line treatment with intramuscular IFN $\beta$-1a $30 \mu \mathrm{g} /$ week, subcutaneous IFN $\beta$-1a $44 \mu \mathrm{g}$ either once/week or three times/ week, subcutaneous IFN $\beta-1 b 250 \mu \mathrm{g}$ every other day, or subcutaneous glatiramer acetate $20 \mathrm{mg} /$ day. There are no data favouring one agent over another.

\section{RRMS}

The goals of therapy in patients with RRMS are to decrease the number and severity of relapses, reduce MRI burden of disease, limit disability progression, and maintain patient quality of life. Four classes of DMT are currently available to treat RRMS: IFN $\beta$ agents; glatiramer acetate; natalizumab, an antialpha ${ }_{4}$-integrin monoclonal antibody; and fingolimod, a sphingosine 1-phosphate receptor modulator. Comparative studies have shown that IFN $\beta$ s are not superior to glatiramer acetate in RRMS ${ }^{78,139}$ Natalizumab and fingolimod are believed to have a more potent effect on clinical and MRI outcomes than first-line agents, but data are limited to one phase III comparative study of fingolimod versus once-weekly IFN $\beta$-1a $30 \mu \mathrm{g} .{ }^{21} \mathrm{In}$ general, these agents are reserved for patients with significant breakthrough disease activity while on an injectable first-line agent, patients who cannot tolerate an injectable DMT, or patients with extremely active RRMS; this is due in part to their riskier side effects and potential toxicities.

The currently recommended first-line agents for RRMS are IFN $\beta$ or glatiramer acetate. The options may broaden as other first-line oral agents become available. As all injectable agents are considered generally comparable in efficacy, the choice of agent will be guided by the side effect profile, and by nonclinical factors, such as dosing schedule, ease of use, reimbursement and patient preference. High-risk RRMS patients (Table 5) with more active or progressive disease may be earlier candidates for fingolimod or natalizumab. This includes patients of African-American ethnicity, who have a worse prognosis ${ }^{140,141}$ and a poorer response to interferons, ${ }^{142,143}$ although there are only limited data on the use of natalizumab in this population. ${ }^{144}$

The timing of the first follow-up visit should be within three to six months of DMT initiation depending on the severity of disease, and patient/physician preferences. All drug-related monitoring should be in accordance with that specified in the product monographs approved by Health Canada. Individual physicians may prefer more frequent follow-ups or additional surveillance. (To access the Canada Vigilance Adverse Reaction Online database go to www.hc-sc.gc.ca/dhp-mps/medeff/ databasdon/index-eng.php.)

A follow-up MRI at 6-12 months following initiation of a DMT is advised to evaluate disease activity on treatment given the prognostic value of that MRI, especially when combined with any clinical signs of renewed activity. This recommendation will be influenced by the accessibility of MRI in different regions of the country.

\section{Model for Determining Treatment Response}

The goal of treatment is to decrease clinical and radiological disease activity and delay long-term progression. As treatment may be especially beneficial earlier in the disease course, treatment non-responders should be identified as soon as possible, ideally within the first year after treatment initiation. The clinical assessment of treatment response should be determined according to two principal factors: the physician's risk assessment for the individual patient; and the level of concern following treatment initiation.

Risk assessment evaluates the level of disease activity and progression at a given point in time and will indicate how aggressive the treatment approach should be. There are no accepted criteria for determining risk empirically; rather, this must be done on a case-by-case basis and is usually based on several factors such as patient age, EDSS, type of breakthrough (relapse, progression, MRI), time between breakthrough events, and prior therapy. For low-risk patients with an inadequate response or poor tolerability to a given first-line agent, it may be reasonable to switch laterally from one DMT to another (e.g. IFN $\beta$ to glatiramer acetate/another IFN $\beta$ or glatiramer acetate to IFN $\beta$ ). For high-risk patients in whom breakthrough disease activity has occurred, treatment escalation to a potentially more potent agent (e.g. IFN $\beta$ to fingolimod or natalizumab) may be reasonable.

During the course of treatment, the level of concern is determined according to the criteria described above for relapses (Table 1), EDSS progression (Table 2) and MRI (Table 3). The level of concern should first be determined at 6-12 months after starting the initial therapy, and at subsequent visits throughout

\section{Table 5: Factors that may be associated with a higher risk of more active/progressive disease in MS patients at diagnosis.}

\footnotetext{
- $\quad$ Relapse severity

$\circ \geq 1$ moderate or severe attack

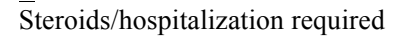

Severe effect on ADLs

$>1$ FS affected

Severe motor/cerebellar/brainstem involvement

- Relapse recovery

- Incomplete

- MRI

$\circ \geq 2 \mathrm{GD}+/$ new T2 lesions or $\geq 2 \mathrm{~T} 1$ hypointense lesions

$\circ \quad \geq 2$ spinal cord lesions

- Brain atrophy

- Older age

- Male sex

- African-American ethnicity
}

$\mathrm{ADL}=$ activities of daily living; $\mathrm{FS}=$ functional systems;

$\mathrm{Gd}+=$ gadolinium-enhancing 
the course of treatment. The frequency of follow-ups is typically every 6 or 12 months but will vary according to the clinical circumstances.

Consideration should be given to switching treatments in a given patient if there is a:

- High level of concern in any one domain (relapses, progression or MRI) (see Tables 1-3)

- Medium level of concern in any two domains

- Low level of concern in all three domains (Figure 1).

Patients who meet any of these criteria should be considered to have a suboptimal treatment response. Adherence to the treatment regimen should be evaluated before switching therapies. The individual patient's reasons for non-adherence (e.g. adverse effects, difficulties with self-injection, perceived lack of benefit, etc.) should be addressed.

\section{Treatment Optimization}

There are two general approaches to optimizing therapy: a lateral switch between two agents in the same line of therapy (e.g. IFN $\beta$ to glatiramer acetate); and treatment escalation to a second-line agent with a potential risk of serious adverse effects (e.g. IFN $\beta$ to fingolimod or natalizumab).

A lateral switch may be indicated for patients who have an adequate treatment response but who have poor tolerability to a particular medication; clinicians should determine if symptomatic management of adverse effects is possible prior to switching therapies. Responders to $\operatorname{IFN} \beta$ who develop persistently high NAbs could be switched to glatiramer acetate. A lateral switch may also be necessary for non-clinical reasons (e.g. change in insurance coverage).

Treatment escalation to a potentially more potent medication may be temporary or permanent. A temporary switch uses an induction strategy to escalate therapy for a pre-determined period to minimize long-term exposure to that drug. For example, a clinician may decide to switch to natalizumab for a set period (e.g. one to two years).

A permanent escalation to a second-line agent would be indicated in patients with a suboptimal response to a first-line therapy, or an aggressive course from disease onset. A change in therapy may also be necessary according to patient preference for a less frequent dosing schedule or for an oral therapy.

The idea of treatment "optimization" is to offer patients the best opportunity of finding a regimen capable of controlling their active disease - both by deciding quickly which treatments are producing suboptimal responses, and by moving to treatments that might offer a better treatment outcome. Although obtaining a disease activity-free (DAF) status is deemed truly "optimal", that may not be possible or feasible for the majority of patients, as even in trials the majority of patients on treatment were not DAF. A more realistic and attainable goal would be to strive for DAF status by defining what is considered to be reasonable disease control, which allows for what is considered to be lowlevel disease activity that is not predictive of further suboptimal response.

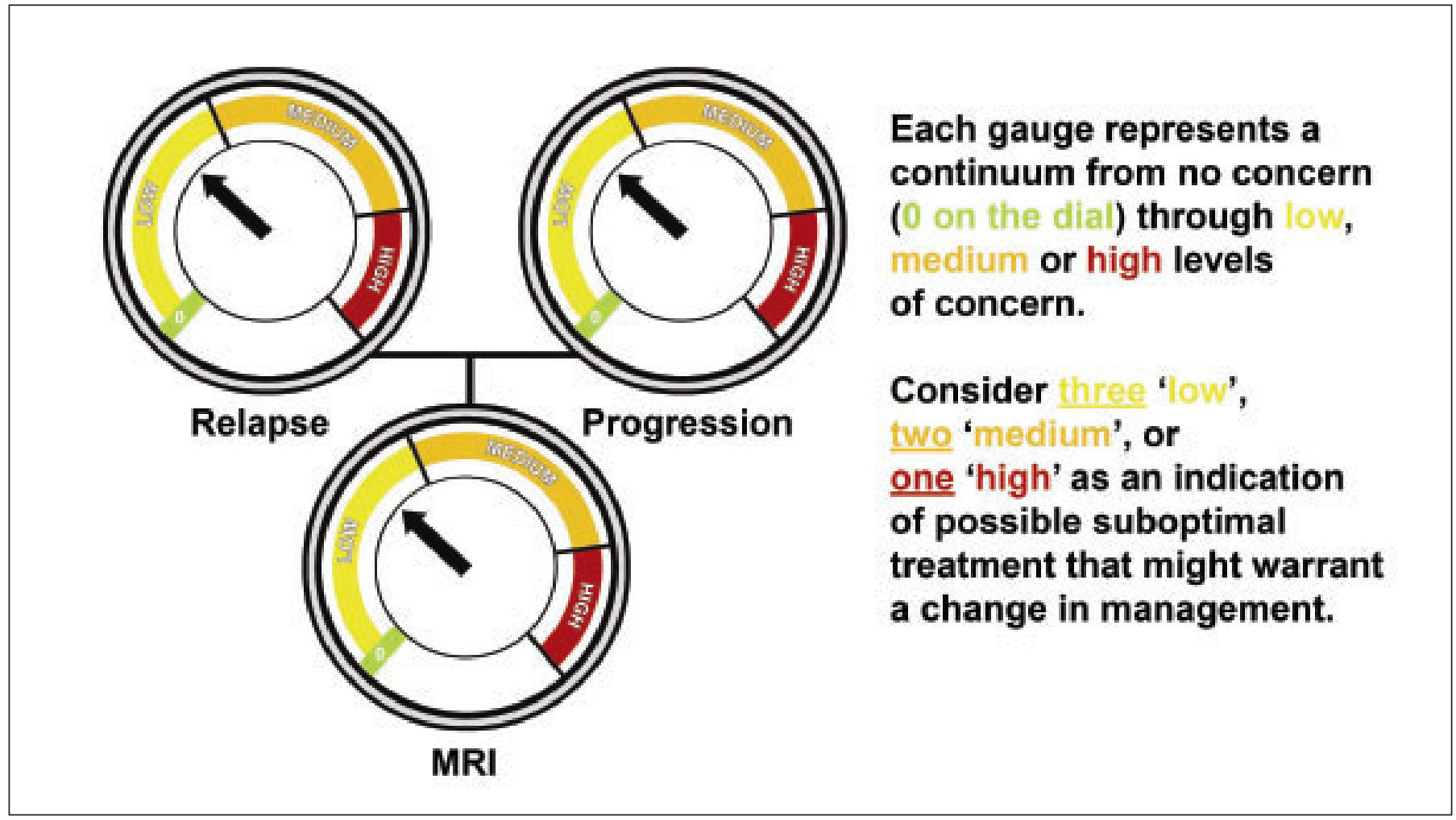

Figure 1: The Canadian treatment optimization model: assessing concern whether to modify a treatment regimen. 


\section{Treatment options}

Figure 2 depicts a suggested treatment approach based on perceived disease severity, level of concern and response to treatment. The choice of agent is determined by the benefit/risk profile of a drug as assessed by the clinician in consultation with the patient. The interferons and glatiramer acetate have overall modest efficacy. While their long-term safety has not been systematically assessed, there have been no major safety signals to date to raise concerns.

Oral drugs in development, such as teriflunomide, ${ }^{145}$ BG$12,{ }^{146}$ and laquinimod, ${ }^{147}$ appear to have treatment effects that are at least comparable to the injectable DMTs. To date their use has been limited to clinical trials and long-term safety data are lacking, but they may be expected to become first-line choices.

The second-line agents fingolimod and natalizumab appear to be more efficacious and possible adverse effects are generally manageable. Of concern, however, are PML associated with natalizumab, and possible cardiovascular events with fingolimod. The long-term safety and efficacy of these agents have not been established.

With respect to escalation from either IFN $\beta$ or glatiramer acetate to natalizumab, retrospective and observational studies have indicated that switching is associated with a significant reduction in clinical and radiological activity. ${ }^{148-152}$ Testing for JC virus antibody ( $\mathrm{Ab}$ ) status is recommended for all natalizumab candidates prior to starting treatment. If $\mathrm{Ab}$ positive, the patient may decide to start natalizumab after being fully informed of the PML risk, or may elect to start with another second-line agent such as fingolimod. Another approach is to start natalizumab for one to two years to reduce the PML risk with the view either to subsequently de-escalate to a first-line agent or switch to fingolimod, depending on the clinical picture. Natalizumab is generally not recommended in patients who are Ab-positive and have received prior immunosuppressants (e.g. mitoxantrone, cyclophosphamide). ${ }^{153} \mathrm{~A}$ switch to another agent is recommended in patients who develop persistent NAbs to natalizumab.

A switch from an IFN $\beta$ to fingolimod has also been shown to produce significant reductions in clinical and radiological activity. ${ }^{154}$ There are no data comparing the relative advantage of fingolimod versus natalizumab. The choice of the optimal agent should be based on the known benefits and risks of each treatment, and in accordance with patient preference.

There are insufficient data regarding the optimal washout period when switching from one therapy to another. No washout period is required when switching among injectable DMTs. There are no data indicating whether a washout period is required when switching from a first-line therapy to natalizumab, or from natalizumab to a subsequent therapy. There is a theoretical risk of PML associated with a shorter washout period when switching to or from natalizumab, but there are no data to support this. The risk of increased disease activity and immune reconstitution inflammatory syndrome (IRIS) upon natalizumab discontinuation ${ }^{155-158}$ need to be carefully considered before switching therapies.

There are no data on the optimal washout period when switching to or from fingolimod. As the use of a more potent agent suggests more severe disease, the interval between therapies will often be determined by the risk of clinical deterioration during the off-treatment period in an individual patient.

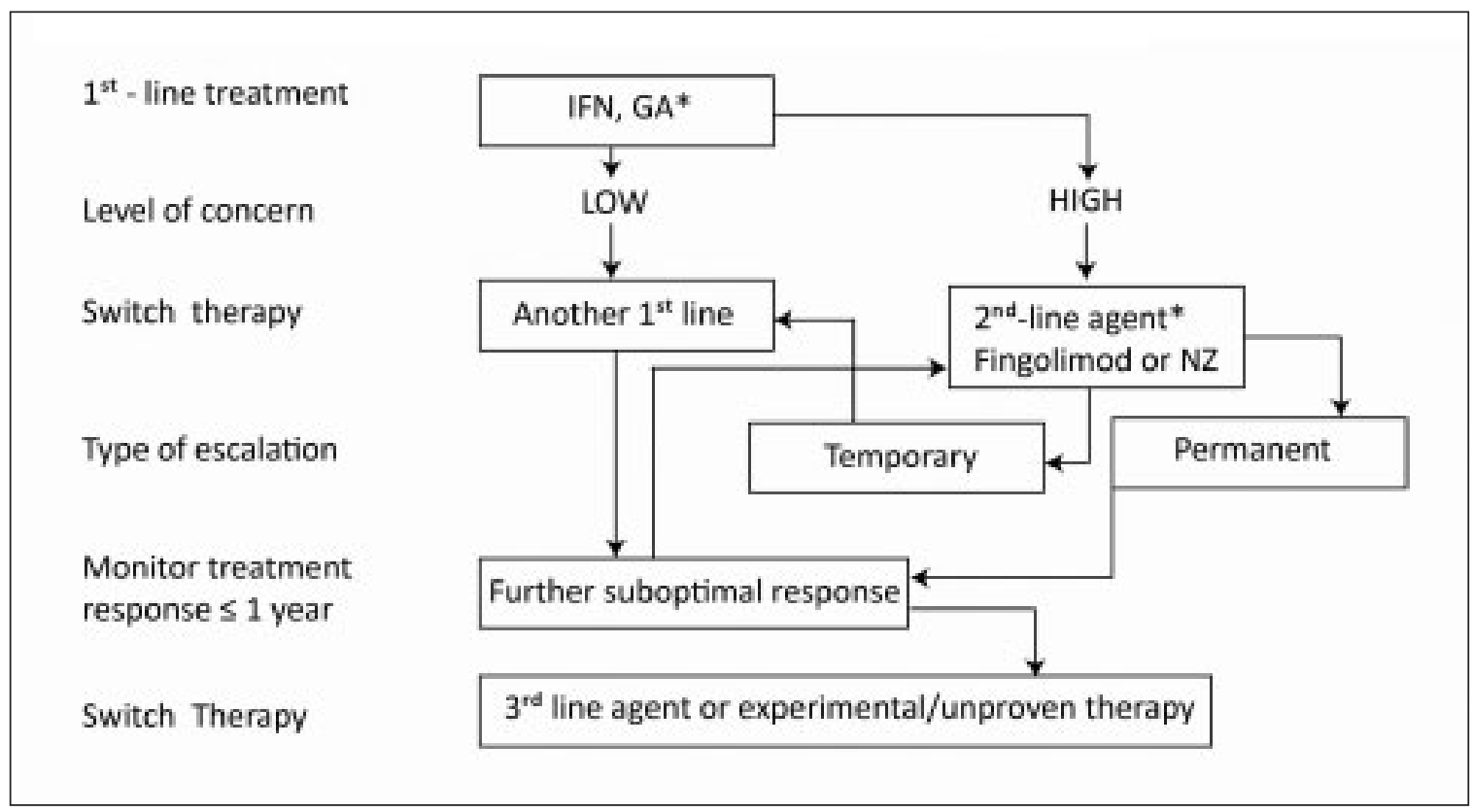

Figure 2: Treatment optimization in a patient with relapsing-remitting MS experiencing a suboptimal response to therapy. *Future options may include teriflunomide, BG-12, laquinimod. IFN=interferon; GA=glatiramer acetate; NZ=natalizumab 


\section{Treatment discontinuation}

While disease-modifying therapy is recommended for all relapsing MS patients, some may elect not to start treatment or may discontinue therapy altogether. Regular monitoring of these patients is recommended and the patient's decision to receive no treatment should be revisited if clinical worsening is detected. There is some evidence to suggest that discontinuing IFN $\beta$ may be associated with a return to pre-treatment levels of disease activity. ${ }^{159}$

The effectiveness of DMTs in patients with high EDSS progression has not been established, and clinicians and patients may elect to discontinue treatment if no further benefit is perceived. ${ }^{160,161}$ It may be prudent to discuss stopping treatment with a patient with significant disease progression (EDSS $>6$ ) who has not experienced a relapse in the preceding two years. However, it should be noted that no clinical criteria have been developed to identify candidates for treatment cessation and the decision to stop therapy must be made on a case-by-case basis and in accordance with the preferences of the patient. A three to six month period off treatment (a "drug holiday"), with subsequent re-evaluation both clinically and with MRI, may be appropriate to aid in this decision.

\section{Additional treatment strategies}

There is limited clinical experience with combination strategies in RRMS. Combining IFN $\beta$ with methotrexate, ${ }^{162}$ IV methylprednisolone, ${ }^{162-164}$ azathioprine ${ }^{165}$ or statins, ${ }^{166}$ or glatiramer acetate with minocycline,${ }^{167}$ has resulted in minimal additional benefit. The CombiRx study found that there was no benefit in combining IFN $\beta$ and glatiramer acetate. ${ }^{168}$ Using natalizumab with another DMT is not recommended, although phase II data suggest that combining it with glatiramer acetate may be safe. ${ }^{169}$ There are preliminary data on the use of rituximab as add-on therapy, ${ }^{170}$ but additional research on the efficacy and safety of this approach is required. There is a phase II study showing that teriflunomide and IFN $\beta$ produce additive responses, especially on MRI, ${ }^{171}$ and a phase III study is underway in patients on IFN $\beta$ who experience breakthrough disease. There are no studies combining fingolimod with another agent.

Patients who have failed to respond adequately to sequential therapy with fingolimod and natalizumab may be considered for mitoxantrone induction, bone-marrow transplantation or a clinical trial with an experimental treatment, such as one of the monoclonal antibodies (e.g. alemtuzumab, ${ }^{172}$ ocrelizumab $^{173}$ ) in development. A careful examination of the risks associated with these treatment approaches is recommended.

\section{Treatment Optimization in Pediatric MS}

The onset of multiple sclerosis during childhood or adolescence is increasingly recognized in Canada and in other countries. ${ }^{174-176}$ The current McDonald criteria now specifically include the view that the revised criteria can be applied in the context of pediatric MS. ${ }^{10}$ Over $95 \%$ of pediatric MS patients present with a relapsing-remitting course ${ }^{177}$ Progressive accrual of disability in a child or adolescent should be considered as exceptionally unlikely to be MS, and clinicians should explore alternative diagnoses.
Treatment strategies for pediatric-onset patients have largely mirrored the current standards of care for adult-onset MS. Corticosteroids are the mainstay of acute therapy for moderate to severe attacks although there are no controlled trials in pediatric subjects. The standard treatment is methylprednisolone 20-30 $\mathrm{mg} / \mathrm{kg}$ (max. $1 \mathrm{~g}$ ) per day IV for three to five days. High-dose oral prednisone in place of IVMP has been used with doses ranging from 100 to $500 \mathrm{mg} /$ day. Subsequent oral steroid taper should be restricted to patients with insufficient resolution of symptoms and kept as short as possible in order to avoid potential side effects, e.g. prednisone $1 \mathrm{mg} / \mathrm{kg}$ as a single daily dose for two days then reduce by $5 \mathrm{mg}$ every two days. Plasma exchange (PLEX) may be considered in patients with severe symptoms not responding sufficiently to high-dose corticosteroids, although clinical experience is limited. Current practice usually consists of five to seven exchanges in total, performed every other day with a 1:1 exchange.

A DMT should be started once a diagnosis of MS has been established irrespective of the age of the child. ${ }^{178}$ First-line options are an IFN $\beta$ or glatiramer acetate. ${ }^{179-181}$ Although a reduction in relapse rate has been described, the available retrospective studies were not designed to evaluate efficacy. Initiation of IFN $\beta$ may follow titration schedules used for adult MS patients with the goal of escalation to the adult dose if tolerated. ${ }^{177}$ Elevations in liver enzymes have been reported more frequently in children aged $<10$ years; monthly monitoring is advised during the titration phase and every three to six months thereafter. Glatiramer acetate may be started at the adult dose of $20 \mathrm{mg}$ /day. ${ }^{177,182}$

An inadequate treatment response is observed in many children with MS. Therapeutic options include switching to another first-line therapy (IFN $\beta$ or GA), or escalating to a second-line agent. ${ }^{183,184}$ Safety considerations are paramount.

It should be noted that all DMTs administered to children have been used off-label, with no clinical trials supporting their efficacy, short- or long-term safety profile. Clinical trials in pediatric MS are urgently needed. Oral therapies are particularly appealing to children and adolescents. Although oral therapies have shown promising efficacy results in adult studies, it is a priority to evaluate the safety and efficacy of such therapies in the pediatric MS population. However, it is not possible to study multiple new therapies in children due to the relatively small population of children available for enrollment. The International Pediatric MS Study Group (IPMSSG) has recently convened to discuss how to overcome the challenges inherent to clinical trials in rare pediatric disorders. Key to the design of such trials will be adequate power, careful consideration of placebo or comparator therapy arms, primary outcome metrics, and secondary outcome evaluations that address physical and cognitive function. Surveillance registries are also needed to evaluate the impact of therapeutic interventions in pediatriconset MS.

\section{SUMMARY}

This refined review helps to better define a scheme for initiating therapy for RRMS and monitoring treatment response in patients to ensure optimized treatment. The approach helps to decide what factors determine a suboptimal treatment response, and offers a strategy for switching among treatments. 
Unacceptable disease "breakthrough" is decided on the basis of determining a "level of concern" rated from 0 to High, and depicted for the three gauges of Relapses, Progression and MRI (Figure 1). A suboptimal response that probably warrants a change in management is represented by one High on any of the gauges, Medium ratings on any two gauges, or Low ratings on all three gauges.

The focus on these three areas of Relapses, Progression and MRI a decade ago has been paralleled by the more recent development of the metric of disease activity-free (DAF) status in clinical trials. Both the level of concern and DAF are reflections of the efficacy that is now achievable with the broader range of treatment choices available to the clinician, although it remains to be determined if striving for DAF status is reasonable, feasible, or will result in better long-term outcomes. It is also unclear if the benefit/risk profile of newer, more potent agents will be favourable over the lifetime course of MS.

The revised CMSWG model and treatment approach probably still need to be tested and validated. An important area of research will be to determine the impact of different treatment strategies on cognitive outcomes. Future recommendations may include cognitive change as a fourth domain for determining the appropriate level of concern for patients on treatment. It is also hoped that ongoing and future therapeutic trials will provide clinicians with more options in managing their patients with primary- and secondary-progressive MS.

\section{*Canadian Multiple Sclerosis Working Group Members}

Pierre Duquette, Centre hospitalier de l'Université de Montréal-Hôpital Notre-Dame, Montreal, Quebec; François Émond, Hôpital de l'Enfant-Jésus, Quebec City, Quebec; Anthony Feinstein, Sunnybrook Health Sciences Centre, Toronto, Ontario; Paul Giacomini, Montreal Neurological Institute and Hospital, Montreal, Quebec; Caroline Geenen, Markham Stouffville Hospital, Markham, Ontario; François Jacques, Clinique Neuro Outaouais, Gatineau, Quebec; Céline Jobin, Hôpital du Sacré-Coeur de Montréal, Montreal, Quebec; Catherine Larochelle, Centre hospitalier de l'Université de Montréal-Hôpital Notre-Dame, Montreal, Quebec; Liesly Lee, Sunnybrook Health Sciences Centre, Toronto, Ontario; Alexander MacDougall, Halifax, Nova Scotia; Heather MacLean, The Ottawa General Hospital, Ottawa, Ontario; Patricia Mandalfino, Kitchener, Ontario; James Marriott, University of Manitoba, Winnipeg, Manitoba; Luanne Metz,* Foothills Medical Centre, Calgary, Alberta; Sarah Morrow, University of Western Ontario, London, Ontario; Mary Lou Myles,* University of Alberta, Edmonton, Alberta; Joël Oger, University of British Columbia Hospital, Vancouver, British Columbia; David Patry, Foothills Medical Centre, Calgary, Alberta; Dawn Pearson, Foothills Medical Centre, Calgary, Alberta; Penelope Smyth, University of Alberta Hospital, Edmonton, Alberta; Daniela Pohl, Children's Hospital of Eastern Ontario, Ottawa, Ontario; Anthony Traboulsee, University of British Columbia Hospital, Vancouver, British Columbia; Helen Tremlett, University of British Columbia Hospital, Vancouver, British Columbia; Sunita Venkateswaran, Children's Hospital of Eastern Ontario, Ottawa, Ontario.

All authors (except where indicated by *) received an honorarium from Novartis Canada.

\section{DISCLOSURES}

All of the authors have reviewed the final version of this manuscript and have agreed with the conclusions. All authors (with the exceptions of LM and MLM) received an honorarium from Novartis Canada for their involvement in the subgroup deliberations and for participation at a roundtable meeting to discuss the development of the contents of this paper. The sponsor provided no input during the development of the manuscript. The CMSWG acknowledges the assistance of Steven Manners of Communications Lansdowne, whose help was made possible through funding from Novartis Canada Pharmaceuticals Inc.

\section{REFERENCES}

1. Freedman MS, Patry DG, Grand'Maison F, et al. Treatment optimization in multiple sclerosis. Can J Neurol Sci. 2004;31: 157-68.

2. Jacobs LD, Beck RW, Simon JHS, et al. Intramuscular interferon beta-1a therapy initiated during a first demyelinating event in multiple sclerosis. N Engl J Med. 2000;343:898-904.

3. Comi G, Filippi M, Barkhof F, et al. Effect of early interferon treatment on conversion to definite multiple sclerosis: a randomised study. Lancet. 2001;357:1576-82.

4. Kappos L, Polman CH, Freedman MS, et al. Treatment with interferon beta- $1 \mathrm{~b}$ delays conversion to clinically definite and McDonald MS in patients with clinically isolated syndromes. Neurology. 2006;67:1242-9.

5. Comi G, Martinelli V, Rodegher M, et al. Effect of glatiramer acetate on conversion to clinically definite multiple sclerosis in patients with clinically isolated syndrome (PreCISe study): a randomised, double-blind, placebo-controlled trial. Lancet. 2009;374:1503-11

6. Comi G, De Stefano N, Freedman MS, et al. Comparison of two dosing frequencies of subcutaneous interferon beta-1a in patients with a first clinical demyelinating event suggestive of multiple sclerosis (REFLEX): a phase 3 randomised controlled trial. Lancet Neurol. 2012;11:33-41.

7. Kinkel RP, Dontchew M, Kollman C, et al. Association between immediate initiation of intramuscular interferon beta-1a at the time of a clinically isolated syndrome and long-term outcomes: a 10-year follow-up of the Controlled High-Risk Avonex Multiple Sclerosis Prevention Study in Ongoing Neurological Surveillance. Arch Neurol. 2012;69:183-90.

8. Kappos L, Freedman MS, Polman CH, et al. Long-term effect of early treatment with interferon beta- $1 \mathrm{~b}$ after a first clinical event suggestive of multiple sclerosis: 5-year active treatment extension of the phase 3 BENEFIT trial. Lancet Neurol. 2009;8: 987-97.

9. Polman $\mathrm{CH}$, Reingold SC, Edan G, et al. Diagnostic criteria for multiple sclerosis: 2005 revisions to the "McDonald Criteria". Ann Neurol. 2005;58:840-6.

10. Polman CH, Reingold SC, Banwell B, et al. Diagnostic criteria for multiple sclerosis: 2010 revisions to the McDonald criteria. Ann Neurol. 2011;69:292-302.

11. Potagas C, Giogkaraki E, Koutsis G, et al. Cognitive impairment in different MS subtypes and clinically isolated syndromes. J Neurol Sci. 2008;267:100-6.

12. Feuillet L, Reuter F, Audoin B, et al. Early cognitive impairment in patients with clinically isolated syndrome suggestive of multiple sclerosis. Mult Scler. 2007;13:124-7.

13. Glanz BI, Holland CM, Gauthier SA, et al. Cognitive dysfunction in patients with clinically isolated syndromes or newly diagnosed multiple sclerosis. Mult Scler. 2007;13:1004-10.

14. Zipoli V, Goretti B, Hakiki B, et al. Cognitive impairment predicts conversion to multiple sclerosis in clinically isolated syndromes. Mult Scler. 2010;16:62-7.

15. Amato MP, Zipoli V, Portaccio E. Multiple sclerosis related cognitive changes: a review of cross-sectional and longitudinal studies. J Neurol Sci. 2006;245:41-6. 
16. Smestada C, Sandvikb L, Landrøc NI, Celius EG. Cognitive impairment after three decades of multiple sclerosis. Eur J Neurol. 2010;17:499-505.

17. Polman $\mathrm{CH}$, O'Connor PW, Havrdova E, et al. A randomized, placebo-controlled trial of natalizumab for relapsing multiple sclerosis. N Engl J Med. 2006;354:899-910.

18. Rudick RA, Stuart WH, Calabresi PA, et al. Natalizumab plus interferon beta-1a for relapsing multiple sclerosis. N Engl J Med. 2006;354:911-23.

19. Kappos L, Bates D, Edan G, et al. Natalizumab treatment for multiple sclerosis: updated recommendations for patient selection and monitoring. Lancet Neurol. 2011;10:745-58.

20. Kappos L, Radue E-W, O'Connor P, et al. A placebo-controlled trial of oral fingolimod in relapsing multiple sclerosis. N Engl J Med. 2010;362:387-401

21. Cohen JA, Barkhof F, Comi G, et al. Oral fingolimod or intramuscular interferon for relapsing multiple sclerosis. N Engl J Med. 2010;362:402-15.

22. Bashir K, Buchwald L, Coyle PK, et al. MS patient management: optimizing the benefits of immunomodulatory therapy. Int J MS Care. 2002;(Suppl):1-7.

23. McDonald WI, Compston A, Edan G, et al. Recommended diagnostic criteria for multiple sclerosis: Guidelines from the International Panel on the Diagnosis of Multiple Sclerosis. Ann Neurol. 2001;50:121-7.

24. Lublin FD, Baier M, Cutter G. Effect of relapses on development of residual deficit in multiple sclerosis. Neurology. 2003;61: 1528-32.

25. Hirst C, Ingram G, Pearson O, Pickersgill T, Scolding N, Robertson $\mathrm{N}$. Contribution of relapses to disability in multiple sclerosis. J Neurol. 2008;255:280-7.

26. Tremlett H, Yousefi M, Devonshire V, Rieckmann P, Zhao Y, UBC Neurologists. Impact of multiple sclerosis relapses on progression diminishes with time. Neurology. 2009;73:1616-23.

27. Confavreux C, Vukusic S, Moreau T, Adeline P. Relapses and progression of disability in multiple sclerosis. N Engl J Med. 2000;343:1430-8.

28. Scalfari A, Neuhaus A, Degenhardt A, et al. The natural history of multiple sclerosis, a geographically based study 10: relapses and long-term disability. Brain. 2010;133:1914-29.

29. Freedman MS. Improving long-term follow-up studies of immunomodulatory therapies. Neurology. 2011;76(1 Suppl 1): S35-8.

30. Thygesen P. Evaluation of drug treatment of disseminated sclerosis. Ugeskr Laeger. 1965;127:1448-50.

31. Inusah S, Sormani MP, Cofield SS, et al. Assessing changes in relapse rates in multiple sclerosis. Mult Scler. 2010;16:1414-21.

32. IFNB Multiple Sclerosis Study Group. Interferon beta-1b is effective in relapsing-remitting multiple sclerosis. I. Clinical results of a multicenter, randomized, double-blind, placebocontrolled trial. Neurology. 1993;43:655-61.

33. Nicholas R, Straube S, Schmidli H, Schneider S, Friede T. Trends in annualized relapse rates in relapsing-remitting multiple sclerosis and consequences for clinical trial design. Mult Scler. 2011;17:1211-7.

34. Tremlett H, Zhao Y, Joseph J, Devonshire V, UBCMS Clinic Neurologists. Relapses in multiple sclerosis are age and timedependent. J Neurol Neurosurg Psychiatry. 2008;79:1368-74.

35. Binquet C, Quantin C, Le Teuff G, Pagliano JF, Abrahamowicz M, Moreau T. The prognostic value of initial relapses on the evolution of disability in patients with relapsing-remitting multiple sclerosis. Neuroepidemiology. 2006;27:45-54.

36. Bosca I, Coret F, Valero C, et al. Effect of relapses over early progression of disability in multiple sclerosis patients treated with beta-interferon. Mult Scler. 2008;14:636-9.

37. Sormani MP, Rio J, Tintore M, et al. Scoring treatment response in patients with relapsing multiple sclerosis Mult Scler. 2012; epublished September 25, 2012.

38. Bergamaschi R, Berzuini C, Romani A, Cosi V. Predicting secondary progression in relapsing-remitting multiple sclerosis: a Bayesian analysis. J Neurol Sci. 2001;189:13-21.
39. Leone MA, Bonissoni S, Collimedaglia L, et al. Factors predicting incomplete recovery from relapses in multiple sclerosis: a prospective study. Mult Scler. 2008;14:485-93.

40. Runmarker B, Andersen O. Prognostic factors in a multiple sclerosis incidence cohort with twenty-five years of follow-up. Brain. 1993;116:117-34

41. Mowry EM, Pesic M, Grimes B, Deen S, Bacchetti P, Waubant E. Demyelinating events in early multiple sclerosis have inherent severity and recovery. Neurology. 2009;72:602-8.

42. Langer-Gould A, Popat RA, Huang SM, et al. Clinical and demographic predictors of long-term disability in patients with relapsing-remitting multiple sclerosis: a systematic review. Arch Neurol. 2006;63:1686-91.

43. Vercellino M, Romagnolo A, Mattioda A, et al. Multiple sclerosis relapses: a multivariable analysis of residual disability determinants. Acta Neurol Scand. 2009;119:126-30.

44. Scott TF, Schramke CJ. Poor recovery after the first two attacks of multiple sclerosis is associated with poor outcome five years later. J Neurol Sci. 2010;292:52-6.

45. Havrdova E, Galetta S, Hutchinson M, et al. Effect of natalizumab on clinical and radiological disease activity in multiple sclerosis: a retrospective analysis of the Natalizumab Safety and Efficacy in Relapsing-Remitting Multiple Sclerosis (AFFIRM) study. Lancet Neurol. 2009;8:254-60.

46. Khatri B, Barkhof F, Comi G, et al. Fingolimod treatment increases the proportion of patients who are free from disease activity in multiple sclerosis compared to IFN-b1a: results from a phase 3, active-controlled study (TRANSFORMS). Presented at the 64th American Academy of Neurology annual meeting, New Orleans LA, April 21-28, 2012; abstract PD5.006.

47. Freedman M, O'Connor P, Wolinsky J, et al. Teriflunomide increases the proportion of patients free from disease activity in the TEMSO phase III study. Presented at the 64th American Academy of Neurology annual meeting, New Orleans LA, April 21-28, 2012; abstract PD5.007.

48. Giovannoni G, Gold R, Kappos L, et al. BG-12 increases the proportion of patients free of clinical and radiologic disease activity in relapsing-remitting multiple sclerosis: findings from the DEFINE study. Presented at the 64th American Academy of Neurology annual meeting, New Orleans LA, April 21-28, 2012; abstract PD5.005.

49. Kurtzke JF. Rating neurologic impairment in multiple sclerosis: an expanded disability status scale (EDSS). Neurology. 1983;33: 1444-52.

50. Fischer JS, Rudick RA, Cutter GR, Reingold SC. The Multiple Sclerosis Functional Composite measure (MSFC): an integrated approach to MS clinical outcomes assessment. Mult Scler. 1999; 5:244-50

51. Kaufman M, Moyer D, Norton J. The significant change for the Timed 25-foot Walk in the multiple sclerosis functional composite. Mult Scler. 2000;6:286-90.

52. Schwid SR, Goodman AD, McDermott MP, Bever CF, Cook SD. Quantitative functional measures in MS: what is a reliable change? Neurology. 2002;58:1294-6.

53. Gijbels D, Eijnde BO, Feys P. Comparison of the 2- and 6-minute walk test in multiple sclerosis. Mult Scler. 2011;17:1269-72.

54. Bosma LVAE, Kragt JJ, Knol DL, Polman CH, Uitdehaag BM. Clinical scales in progressive MS: predicting long-term disability. Mult Scler. 2012;18:345-50.

55. Goodman AD, Brown TR, Edwards KR, et al. A phase 3 trial of extended release oral dalfampridine in multiple sclerosis. Ann Neurol. 2010;68:494-502.

56. Hobart JC, Riazi A, Lamping DL, Fitzpatrick R, Thompson AJ. Measuring the impact of MS on walking ability: the 12-Item MS Walking Scale (MSWS-12). Neurology. 2003;60:31-6.

57. International Federation of Multiple Sclerosis Societies. Symposium on a minimal record of disability for multiple sclerosis. Vancouver, Canada, September 11, 12, 1983. Acta Neurol Scand Suppl. 1984;101:1-217.

58. Schwartz CE, Vollmer T, Lee H. Reliability and validity of two selfreport measures of impairment and disability for MS. North American Research Consortium on Multiple Sclerosis Outcomes Study Group. Neurology. 1999;52:63-70. 
59. Invernizzi $\mathrm{P}$, Bertolasi L, Bianchi MR, Turatti M, Gajofatto A, Benedetti MD. Prognostic value of multimodal evoked potentials in multiple sclerosis: the EP score. J Neurol. 2011; 258:1933-9.

60. Teunissen CE, Khalil M. Neurofilaments as biomarkers in multiple sclerosis. Mult Scler. 2012;18:552-6.

61. Bergamaschi R, Quaglini S, Tavazzi E, et al. Immunomodulatory therapies delay disease progression in multiple sclerosis. Mult Scler. 2012; epublished May 31, 2012.

62. La Mantia L, Munari LM, Lovati R. Glatiramer acetate for multiple sclerosis. Cochrane Database Syst Rev. 2010 May 12;(5): CD004678.

63. Shirani A, Zhao Y, Karim ME, et al. Association between use of interferon beta and progression of disability in patients with relapsing-remitting multiple sclerosis. JAMA. 2012;308:247-56.

64. Goodin DS, Ebers GC, Cutter G, et al. Cause of death in MS: longterm follow-up of a randomised cohort, 21 years after the start of the pivotal IFN $\beta-1 b$ study. BMJ Open. 2012;2: e001972.

65. Rio J, Nos C, Tintore M, et al. Assessment of different treatment failure criteria in a cohort of relapsing-remitting multiple sclerosis patients treated with interferon $\beta$ : implications for clinical trials. Ann Neurol. 2002;52:400-6.

66. Rio J, Comabella M, Montalban X. Predicting responders to therapies for multiple sclerosis. Nat Rev Neurol. 2009;5:553-60.

67. Dayal AS, Jensen MA, Lledo A, Arnason BG. Interferon-gammasecreting cells in multiple sclerosis patients treated with interferon beta-1b. Neurology. 1995;45:2173-7.

68. Rudick RA, Lee J-C, Cutter GR, et al. Disability progression in a clinical trial of relapsing-remitting multiple sclerosis. Arch Neurol. 2010;67:1329-35.

69. Ebers GC, Heigenhauser L, Daumer M, Lederer C, Noseworthy JH. Disability as an outcome in MS clinical trials. Neurology. 2008; 71:624-31.

70. Rudick RA, Lee JC, Simon J, Ransohoff RM, Fisher E. Defining interferon beta response status in multiple sclerosis patients. Ann Neurol. 2004;56:548-55.

71. Pozzilli C, Prosperini L, Sbardella E, De Giglio L, Onesti E, Tomassini V. Post-marketing survey on clinical response to interferon beta in relapsing multiple sclerosis: the Roman experience. Neurol Sci. 2005;26 Suppl 4:S174-8.

72. Tomassini V, Paolillo A, Russo P, et al. Predictors of long-term clinical response to interferon beta therapy in relapsing multiple sclerosis. J Neurol. 2006;253:287-93.

73. Prosperini L, Gallo V, Petsas N, Borriello G, Pozzilli C. One-year MRI scan predicts clinical response to interferon beta in multiple sclerosis. Eur J Neurol. 2009;16:1202-9.

74. Rio J, Rovira A, Tintore M, et al. Relationship between MRI lesion activity and response to IFN-beta in relapsing-remitting multiple sclerosis patients. Mult Scler. 2008;14:479-84.

75. Riddell CA, Zhao Y, Li DK, et al. Evaluation of safety monitoring guidelines based on MRI lesion activity in multiple sclerosis. Neurology. 2011;77:2089-96.

76. PRISMS (Prevention of Relapses and Disability by Interferon beta1a Subcutaneously in Multiple Sclerosis) Study Group. Randomised double-blind placebo-controlled study of interferon beta-1a in relapsing/remitting multiple sclerosis. Lancet. 1998; 352:1498-504.

77. Simon JH, Li D, Traboulsee A, et al. Standardized MR imaging protocol for multiple sclerosis: Consortium of MS Centers consensus guidelines. AJNR Am J Neuroradiol. 2006;27:455-61.

78. Mikol DD, Barkhof F, Chang P, et al. Comparison of subcutaneous interferon beta-1a with glatiramer acetate in patients with relapsing multiple sclerosis (the REbif vs Glatiramer Acetate in Relapsing MS Disease [REGARD] study): a multicentre, randomised, parallel, open-label trial. Lancet Neurol. 2008;7: 903-14.

79. Gauthier SA, Berger AM, Liptak Z, et al. Rate of brain atrophy in benign vs early multiple sclerosis. Arch Neurol. 2009;66:234-7.

80. Lukas C, Minneboo A, de Groot V, et al. Early central atrophy rate predicts 5 year clinical outcome in multiple sclerosis. J Neurol Neurosurg Psychiatry. 2010;81:1351-6.
81. Prakash RS, Snook EM, Lewis JM, Motl RW, Kramer AF. Cognitive impairments in relapsing-remitting multiple sclerosis: a meta-analysis. Mult Scler. 2008;14:1250-61.

82. Benedict RHB, Zivadinov R. Risk factors for and management of cognitive dysfunction in multiple sclerosis. Nat Rev Neurol. 2011;7:332-42

83. Kalmar JH, Gaudino EA, Moore NB, Halper J, Deluca J. The relationship between cognitive deficits and everyday functional activities in multiple sclerosis. Neuropsychology. 2008;22: 442-9.

84. Rao SM, Leo GJ, Ellington L, Nauertz T, Bernardin L, Unverzagt F. Cognitive dysfunction in multiple sclerosis. II. Impact on employment and social functioning. Neurology. 1991;41:692-6.

85. Benedict RH, Wahlig E, Bakshi R, et al. Predicting quality of life in multiple sclerosis: accounting for physical disability, fatigue, cognition, mood disorder, personality, and behavior change. J Neurol Sci. 2005;231:29-34.

86. Smith A. Symbol Digit Modalities Test: Manual. Western Psychological Services, Los Angeles CA, 1982.

87. Benedict RHB, Duquin JA, Jurgensen S, et al. Repeated assessment of neuropsychological deficits in multiple sclerosis using the Symbol Digit Modalities Test and the MS Neuropsychological Screening Questionnaire. Mult Scler. 2008;14:940-6.

88. Morrow SA, O'Connor PW, Polman CH, et al. Evaluation of the symbol digit modalities test (SDMT) and MS neuropsychological screening questionnaire (MSNQ) in natalizumabtreated MS patients over 48 weeks. Mult Scler. 2010;16: 1385-92.

89. Morrow SA, Drake A, Zivadinov R, Munschauer F, WeinstockGuttman B, Benedict RH. Predicting loss of employment over three years in multiple sclerosis: clinically meaningful cognitive decline. Clin Neuropsychol. 2010;24:1131-45.

90. Heesen C, Schulz KH, Fiehler J, et al. Correlates of cognitive dysfunction in multiple sclerosis. Brain Behav Immun. 2010;24: 1148-55.

91. Carone DA, Benedict RHB, Munschauer FE, Fishman I, Weinstock-Guttman B. Interpreting patient/informant discrepancies of reported cognitive symptoms in MS. J Int Neuropsychol Soc. 2005;11:574-83.

92. Deloire MSA, Bonnet MC, Salort E, et al. How to detect cognitive dysfunction at early stages of multiple sclerosis? Mult Scler. 2006; $12: 445-52$

93. Arnett PA, Higginson CI, Voss WD, et al. Depressed mood in multiple sclerosis: Relationship to capacity-demanding memory and attentional functioning. Neuropsychology. 1999;13:434-46.

94. Benedict RHB, Fishman I, McClellan MM, Bakshi R, WeinstockGuttman B. Validity of the Beck Depression Inventory - Fast Screen in multiple sclerosis. Mult Scler. 2003;9:393-6.

95. Fatigue guidelines development panel of the multiple sclerosis council for clinical practice guidelines. Fatigue and multiple sclerosis. Evidence-based management strategies for fatigue in multiple sclerosis. Washington, DC: Paralyzed Veterans of America, 1998

96. Ehde DM, Kraft GH, Chwastiak L, et al. Efficacy of paroxetine in treating major depressive disorder in persons with multiple sclerosis. Gen Hosp Psychiatry. 2008;30:40-8.

97. Benedetti F, Campori E, Colombo C, Smeraldi E. Fluvoxamine treatment of major depression associated with multiple sclerosis. J Neuropsychiatry Clin Neurosci. 2004;16:364-6.

98. Mohr DC, Boudewyn AC, Goodkin DE, Bostrom A, Epstein L. Comparative outcomes for individual cognitive-behavior therapy, supportive-expressive group psychotherapy, and sertraline for the treatment of depression in multiple sclerosis. J Consult Clin Psychol. 2001;69:942-9.

99. Barak Y, Ur E, Achiron A. Moclobemide treatment in multiple sclerosis patients with comorbid depression: an open-label safety trial. J Neuropsychiatry Clin Neurosci. 1999;11:271-3.

100.Dean G. A double-blind trial with an antidepressant drug, imipramine, in multiple sclerosis. S Afr Med J. 1969;43:86-7.

101. Schiffer RB, Wineman NM. Antidepressant pharmacotherapy of depression associated with multiple sclerosis. Am J Psychiatry. 1990;147:1493-7. 
102.Patti F, Amato MP, Bastianello S, et al. Effects of immunomodulatory treatment with subcutaneous interferon beta-1a on cognitive decline in mildly disabled patients with relapsingremitting multiple sclerosis. Mult Scler. 2010;16: 68-77.

103. Schwid SR, Goodman AD, Weinstein A, McDermott MP, Johnson $\mathrm{KP}$; for the Copaxone Study Group. Cognitive function in relapsing multiple sclerosis: Minimal changes in a 10 -year clinical trial. J Neurol Sci. 2007;255:57-63.

104. Fischer JS, Priore RL, Jacobs LD, et al. Neuropsychological effects of interferon beta-1a in relapsing multiple sclerosis. Multiple Sclerosis Collaborative Research Group. Ann Neurol. 2000;48: 885-92.

105. Weinstock-Guttman B, Galetta SL, Giovannoni G, et al. Additional efficacy endpoints from pivotal natalizumab trials in relapsingremitting MS. J Neurol. 2012; 259: 898-905.

106. Fox EJ, Sullivan HC, Gazda SK, et al. A single-arm, open-label study of alemtuzumab in treatment-refractory patients with multiple sclerosis. Eur J Neurol. 2012;19:307-11.

107. He D, Zhou H, Guo D, Hao Z, Wu B. Pharmacologic treatment for memory disorder in multiple sclerosis. Cochrane Database Syst Rev. 2011 Oct 5;(10):CD008876.

108. Morrow SA, Jurgensen S, Forrestal F, Munchauer FE, Benedict RH. Effects of acute relapses on neuropsychological status in multiple sclerosis patients. J Neurol. 2011;258:1603-8.

109. Jungedal R, Lundkvist M, Engdahl E, et al. Prevalence of anti-drug antibodies against interferon beta has decreased since routine analysis of neutralizing antibodies became clinical practice. Mult Scler. 2012;18:1775-81.

110. Hegen H, Schleiser M, Gneiss C, et al. Persistency of neutralizing antibodies depends on titer and interferon-beta preparation. Mult Scler. 2012;18:610-5.

111. Boz C, Oger J, Gibbs E, Grossberg SE, Neurologists of the UBC MS Clinic. Reduced effectiveness of long-term interferon-beta treatment on relapses in neutralizing antibody-positive multiple sclerosis patients: a Canadian multiple sclerosis clinic-based study. Mult Scler. 2007;13:1127-37.

112. Hartung HP, Freedman MS, Polman $\mathrm{CH}$, et al. Interferon $\beta-1 b-$ neutralizing antibodies 5 years after clinically isolated syndrome. Neurology. 2011;77:835-43.

113. Farrell RA, Espasandin M, Lakdawala N, Creeke PI, Worthington $\mathrm{V}$, Giovannoni $\mathrm{G}$. Incorporation of an interferon- $\beta$ neutralizing antibody assay into routine clinical practice. Mult Scler. 2011; 17:1333-40.

114. Calabresi PA, Giovannoni G, Confavreux C, et al. The incidence and significance of anti-natalizumab antibodies: results from AFFIRM and SENTINEL. Neurology. 2007;69:1391-403.

115. Deisenhammer F. Neutralizing antibodies to interferon-beta and other immunological treatments for multiple sclerosis: prevalence and impact on outcomes. CNS Drugs. 2009;23: 379-96.

116. Teitelbaum D, Brenner T, Abramsky O, Aharoni R, Sela M, Arnon $\mathrm{R}$. Antibodies to glatiramer acetate do not interfere with its biological functions and therapeutic efficacy. Mult Scler. 2003; 9:592-9

117. Acheson ED, Bachrach CA, Wright FM. Some comments on the relationship of the distribution of multiple sclerosis to latitude, solar radiation, and other variables. Acta Psychiatr Scand Suppl. 1960;35:132-47.

118. Munger KL, Levin LI, Hollis BW, Howard NS, Ascherio A. Serum 25-hydroxyvitamin D levels and risk of multiple sclerosis. JAMA. 2006;296:2832-8.

119. Kragt J, van Amerongen B, Killestein J, et al. Higher levels of 25hydroxyvitamin D are associated with a lower incidence of multiple sclerosis only in women. Mult Scler. 2009;15:9-15.

120. Bhalla AK, Amento EP, Clemens TL, Holick MF, Krane SM. Specific high affinity receptors for 1,25-dihydroxyvitamin D3 in human peripheral blood mononuclear cells: presence in monocytes and induction in T lymphocytes following activation. J Clin Endocrinol Metab. 1983;57:1308-10.

121. Vedman CM, Cantorna MT, DeLuca HF. Expression of 1,25dihydroxyvitamin $\mathrm{D}(3)$ receptor in the immune system. Arch Biochem Biophys. 2000;374:334-8.
122. Chen S, Sims GP, Chen XX, Gu YY, Chen S, Lipsky PE. Modulatory effect of 1,25-dihydroxyvitamin D3 on human B cell differentiation. J Immunol. 2007;179:1634-47.

123. Rucker D, Allan JA, Fick GH, Hanley DA. Vitamin D insufficiency in a population of healthy western Canadians. Can Med Assoc J. 2002;166:1517-24.

124. Webb AR, Kline L, Holick MF. Influence of season and latitude on the cutaneous synthesis of vitamin-D3 - exposure to winter sunlight in Boston and Edmonton will not promote vitaminD3 synthesis in human skin. J Clin Endocrinol Metab. 1988;67: 373-8.

125. Tremlett H, van der Mei IA, Pittas F, et al. Monthly ambient sunlight, infections and relapse rates in multiple sclerosis. Neuroepidemiology. 2008;31:271-9.

126. D'hooghe M, Haentjens P, Nagels G, Garmyn M, De Keyser J. Sunlight exposure and sun sensitivity associated with disability progression in multiple sclerosis. Mult Scler. 2012;18:451-9.

127. Smolders J, Menheere P, Kessels A, Damoiseaux J, Hupperts R. Association of vitamin D metabolite levels with relapse rate and disability in multiple sclerosis. Mult Scler. 2008;14:1220-4

128. Simpson S, Taylor B, Blizzard L, et al. Higher levels of serum 25hydroxyvitamin D3 are associated with a reduced risk of relapse in multiple sclerosis. Ann Neurol. 2010;68:193-203.

129. Mowry EM, Waubant E, McCulloch CE, et al. Vitamin D status predicts new brain magnetic resonance imaging activity in multiple sclerosis. Ann Neurol. 2012;72:234-40.

130. Soilu-Hanninen M, Aivo J, Lindstrom BM, et al. A randomised, double blind, placebo controlled trial with vitamin D3 as an add on treatment to interferon $\beta-1 b$ in patients with multiple sclerosis. J Neurol Neurosurg Psychiatry. 2012;83:565-71.

131. Stein MS, Liu Y, Gray OM, et al. A randomized trial of high-dose vitamin D2 in relapsing-remitting multiple sclerosis. Neurology. 2011;77:1611-8.

132. Mosayebi G, Ghazavi A, Ghasami K, Jand Y, Kokhaei P. Therapeutic effect of vitamin D3 in multiple sclerosis patients. Immunol Invest. 2011;40:627-39.

133. Lucas RM, Ponsonby AL, Dear K, et al. Sun exposure and vitamin $\mathrm{D}$ are independent risk factors for CNS demyelination. Neurology. 2011;76:540-8.

134. Hart PH. Vitamin D supplementation, moderate sun exposure, and control of immune diseases. Discov Med. 2012;13:397-404.

135. Smolders J, Hupperts R, Barkhof F, et al. Efficacy of vitamin D(3) as add-on therapy in patients with relapsing-remitting multiple sclerosis receiving subcutaneous interferon beta-1a: a Phase II, multicenter, double-blind, randomized, placebo-controlled trial. J Neurol Sci. 2011;311:44-9.

136. Dorr J, Ohlraun S, Skarabis H, Paul F. Efficacy of vitamin D supplementation in multiple sclerosis (EVIDIMS Trial): study protocol for a randomized controlled trial. Trials. 2012 Feb 8; $13: 15$.

137. Burton JM, Kimball S, Vieth R, et al. A phase I/II dose-escalation trial of vitamin D3 and calcium in multiple sclerosis. Neurology. 2010;74:1852-9

138. Bischoff-Ferrari HA, Giovannucci E, Willett WC, Dietrich T, Dawson-Hughes B. Estimation of optimal serum concentrations of 25-hydroxyvitamin D for multiple health outcomes. Am J Clin Nutr. 2006;84:18-28.

139. O'Connor P, Filippi M, Arnason B, et al. 250 microg or 500 microg interferon beta- $1 \mathrm{~b}$ versus $20 \mathrm{mg}$ glatiramer acetate in relapsingremitting multiple sclerosis: a prospective, randomised, multicentre study. Lancet Neurol. 2009;8:889-97.

140. Kister I, Chamot E, Bacon JH, et al. Rapid disease course in African Americans with multiple sclerosis. Neurology. 2010;75:217-23.

141. Naismith RT, Trinkaus K, Cross AH. Phenotype and prognosis in African-Americans with multiple sclerosis: a retrospective chart review. Mult Scler. 2006;12:775-81

142. Klineova S, Nicholas J, Walker A. Response to disease modifying therapies in African Americans with multiple sclerosis. Ethn Dis. 2012;22:221-5

143. Cree BA, Al-Sabbagh A, Bennett R, Goodin D. Response to interferon beta-1a treatment in African American multiple sclerosis patients. Arch Neurol. 2005;62:1681-3. 
144. Cree BA, Stuart WH, Tornatore CS, et al. Efficacy of natalizumab therapy in patients of African descent with relapsing multiple sclerosis: analysis of AFFIRM and SENTINEL data. Arch Neurol. 2011;68:464-8.

145. O'Connor P, Wolinsky JS, Confavreux C, et al. Randomized trial of oral teriflunomide for relapsing multiple sclerosis. N Engl J Med. 2011;365:1293-303.

146. Gold R, Kappos L, Arnold DL, et al. Placebo-controlled phase 3 study of oral BG-12 for relapsing multiple sclerosis. N Engl J Med. 2012;367:1098-107.

147. Comi G, Jeffery D, Kappos L, et al. Placebo-controlled trial of oral laquinimod for multiple sclerosis. N Engl J Med. 2012;366: $1000-9$.

148. Putzki N, Yaldizli O, Buhler R, Schwegler G, Curtius D, Tettenborn B. Natalizumab reduces clinical and MRI activity in multiple sclerosis patients with high disease activity: results from a multicenter study in Switzerland. Eur Neurol. 2010;63:101-6.

149. Prosperini L, Gianni C, Leonardi L, et al. Escalation to natalizumab or switching among immunomodulators in relapsing multiple sclerosis. Mult Scler. 2012;18:64-71.

150.Castillo-Trivino T, Mowry EM, Gajofatto A, et al. Switching multiple sclerosis patients with breakthrough disease to secondline therapy. PLoS One. 2011;6:e16664.

151.Krysko KM, O'Connor PW. The Toronto observational study of natalizumab in multiple sclerosis. Can J Neurol Sci. 2011;38: 422-8.

152. Sangalli F, Moiola L, Bucello S, et al. Efficacy and tolerability of natalizumab in relapsing-remitting multiple sclerosis patients: a post-marketing observational study. Neurol Sci. 2011;31 Suppl 3:299-302.

153. Sorensen PS, Bertolotto A, Edan G, et al. Risk stratification for progressive multifocal leukoencephalopathy in patients treated with natalizumab. Mult Scler. 2012;18:143-52.

154. Khatri B, Barkhof F, Comi G, et al. Comparison of fingolimod with interferon beta-1a in relapsing-remitting multiple sclerosis: a randomised extension of the TRANSFORMS study. Lancet Neurol. 2011;10:520-9.

155.Killestein J, Vennegoor A, Strijbis EM, et al. Natalizumab drug holiday in multiple sclerosis: poorly tolerated. Ann Neurol. 2010;68:392-5

156. Miravalle A, Jensen R, Kinkel RP. Immune reconstitution inflammatory syndrome in patients with multiple sclerosis following cessation of natalizumab therapy. Arch Neurol. 2011; 68:186-91

157. West TW, Cree BA. Natalizumab dosage suspension: are we helping or hurting? Ann Neurol. 2010;68:395-9.

158. Schaaf SM, Pitt D, Racke MK. What happens when natalizumab therapy is stopped? Expert Rev Neurother. 2011;11:1247-50.

159. Siger M, Durko A, Nicpan A, Konarska M, Grudziecka M, Selmaj K. Discontinuation of interferon beta therapy in multiple sclerosis patients with high pre-treatment disease activity leads to prompt return to previous disease activity. J Neurol Sci. 2011; 303:50-2

160.Lonergan R, Kinsella K, Duggan M, Jordan S, Hutchinson M, Tubridy N. Discontinuing disease-modifying therapy in progressive multiple sclerosis: can we stop what we have started? Mult Scler. 2009; 15:1528-31

161. O'Rourke KE, Hutchinson M. Stopping beta-interferon therapy in multiple sclerosis: an analysis of stopping patterns. Mult Scler. 2005; $11: 46-50$

162. Cohen JA, Imrey PB, Calabresi PA, et al. Results of the Avonex Combination Trial (ACT) in relapsing-remitting MS. Neurology. 2009;72: 535-41.

163. Sorensen PS, Mellgren SI, Svenningsson A, et al. NORdic trial of oral Methylprednisolone as add-on therapy to Interferon beta-1a for treatment of relapsing-remitting Multiple Sclerosis (NORMIMS study): a randomised, placebo-controlled trial. Lancet Neurol. 2009;8:519-29.

164. Ravnborg M, Sorensen PS, Andersson M, et al. Methylprednisolone in combination with interferon beta-1a for relapsing-remitting multiple sclerosis (MECOMBIN study): a multicentre, doubleblind, randomised, placebo-controlled, parallel-group trial. Lancet Neurol. 2010;9:672-80.
165. Havrdova E, Zivadinov R, Krasensky J, et al. Randomized study of interferon beta-1a, low-dose azathioprine, and low-dose corticosteroids in multiple sclerosis. Mult Scler. 2009;15:965-76.

166. Wang J, Xiao Y, Luo M, Luo H. Statins for multiple sclerosis. Cochrane Database Syst Rev. 2011 Dec 7;(12):CD008386.

167. Metz LM, Li D, Traboulsee A, et al. Glatiramer acetate in combination with minocycline in patients with relapsing-remitting multiple sclerosis: results of a Canadian, multicenter, double-blind, placebo-controlled trial. Mult Scler. 2009;15: 1183-94.

168. Lindsey J, Scott T, Lynch S, et al. The CombiRx trial of combined therapy with interferon and glatiramer cetate in relapsing remitting MS: Design and baseline characteristics. Mult Scler. Relat Disord 2012;1:81-6.

169. Goodman AD, Rossman H, Bar-Or A, et al. GLANCE: results of a phase 2, randomized, double-blind, placebo-controlled study. Neurology. 2009;72:806-12.

170. Naismith RT, Piccio L, Lyons JA, et al. Rituximab add-on therapy for breakthrough relapsing multiple sclerosis: a 52-week phase II trial. Neurology. 2010;74:1860-7.

171. Freedman MS, Wolinsky JS, Wamil B, et al. Teriflunomide added to interferon- $\beta$ in relapsing multiple sclerosis: A randomized phase II trial. Neurology. 2012;78:1877-85.

172. Coles AJ, Twyman CL, Arnold DL, et al. Alemtuzumab for patients with relapsing multiple sclerosis after disease-modifying therapy: a randomised controlled phase 3 trial. Lancet. 2012;380: 1829-39.

173. Kappos L, Li D, Calabresi PA, et al. Ocrelizumab in relapsingremitting multiple sclerosis: a phase 2, randomised, placebocontrolled, multicentre trial. Lancet. 2011;378:1779-87.

174. Banwell B, Kennedy J, Sadovnick D, et al. Incidence of acquired demyelination of the CNS in Canadian children. Neurology. 2009;72:232-9.

175. Pohl D, Hennemuth I, von Kries R, Hanefeld F. Paediatric multiple sclerosis and acute disseminated encephalomyelitis in Germany: results of a nationwide survey. Eur J Pediatr. 2007;166:405-12.

176. Langer-Gould A, Zhang JL, Chung J, Yeung Y, Waubant E, Yao J. Incidence of acquired CNS demyelinating syndromes in a multiethnic cohort of children. Neurology. 2011;77:1143-8.

177. Banwell B, Ghezzi A, Bar-Or A, Mikaeloff Y, Tardieu M. Multiple sclerosis in children: clinical diagnosis, therapeutic strategies, and future directions. Lancet Neurol. 2007;6:887-902.

178. Chitnis T, Tenembaum S, Banwell B, et al. Consensus statement: evaluation of new and existing therapeutics for pediatric multiple sclerosis. Mult Scler. 2012;18:116-27.

179. Ghezzi A, Amato MP, Capobianco M, et al. Disease-modifying drugs in childhood-juvenile multiple sclerosis: results of an Italian co-operative study. Mult Scler. 2005;11:420-4.

180. Tenembaum SN, Segura MJ. Interferon beta-1a treatment in childhood and juvenile-onset multiple sclerosis. Neurology. 2006;67:511-3.

181. Banwell B, Reder AT, Krupp L, et al. Safety and tolerability of interferon beta-1b in pediatric multiple sclerosis. Neurology. 2006;66:472-6

182. Kornek B, Bernert G, Balassy C, Geldner J, Prayer D, Feucht M. Glatiramer acetate treatment in patients with childhood and juvenile onset multiple sclerosis. Neuropediatrics. 2003;34: $120-6$.

183. Banwell B, Bar-Or A, Giovannoni G, Dale RC, Tardieu M. Therapies for multiple sclerosis: considerations in the pediatric patient. Nat Rev Neurol. 2011;7:109-22.

184. Yeh EA, Waubant E, Krupp LB, et al. Multiple sclerosis therapies in pediatric patients with refractory multiple sclerosis. Arch Neurol. 2011;68:437-44. 